IZA DP No. 5054

Employer Learning, Productivity and the Earnings Distribution: Evidence from Performance Measures

Lisa B. Kahn

Fabian Lange

July 2010 


\title{
Employer Learning, Productivity and the Earnings Distribution: Evidence from Performance Measures
}

\author{
Lisa B. Kahn \\ Yale University \\ Fabian Lange \\ Yale University \\ and IZA
}

\author{
Discussion Paper No. 5054 \\ July 2010
}

(revised version: August 2013 - http://ftp.iza.org/dp5054 rev.pdf)

IZA

P.O. Box 7240

53072 Bonn

Germany

Phone: +49-228-3894-0

Fax: +49-228-3894-180

E-mail: iza@iza.org

Any opinions expressed here are those of the author(s) and not those of IZA. Research published in this series may include views on policy, but the institute itself takes no institutional policy positions.

The Institute for the Study of Labor (IZA) in Bonn is a local and virtual international research center and a place of communication between science, politics and business. IZA is an independent nonprofit organization supported by Deutsche Post Foundation. The center is associated with the University of Bonn and offers a stimulating research environment through its international network, workshops and conferences, data service, project support, research visits and doctoral program. IZA engages in (i) original and internationally competitive research in all fields of labor economics, (ii) development of policy concepts, and (iii) dissemination of research results and concepts to the interested public.

IZA Discussion Papers often represent preliminary work and are circulated to encourage discussion. Citation of such a paper should account for its provisional character. A revised version may be available directly from the author. 


\section{ABSTRACT}

\section{Employer Learning, Productivity and the Earnings Distribution: Evidence from Performance Measures*}

Two ubiquitous empirical regularities in pay distributions are that the variance of wages increases with experience, and innovations in wage residuals have a large, unpredictable component. The leading explanations for these patterns are that over time, either firms learn about worker productivity but productivity remains fixed or workers' productivities themselves evolve heterogeneously. In this paper, we seek to disentangle these two models and place magnitudes on their relative importance. We derive a dynamic model of learning and productivity that nests both models and allows them to coexist. We estimate our model on a 20-year panel of pay and performance measures from a single, large firm (the Baker-GibbsHolmstrom data). Incorporating performance measures yields two key innovations. First, the panel structure implies that we have repeat measures of correlates of productivity, as opposed to the empirical evidence on employer learning which uses one fixed measure. Second, we can separate productivity from pay, whereas the previous literature on productivity evolution could not. We find that both models are important in explaining the data. However, the predominant effect is that worker productivity evolves idiosyncratically over time, implying firms must continuously learn about a moving target. Therefore, while the majority of pay dispersion is driven by variation in individual productivity, wages differ significantly from individual productivity at all experience levels due to imperfect information. We believe this represents a significant reinterpretation of the empirical literature on employer learning.

JEL Classification: D21, D83, J24, J33

Keywords: employer learning, productivity, performance evaluations, personnel

Corresponding author:

Fabian Lange

Department of Economics

Yale University

37 Hillhouse Ave

New Haven, CT 06511

USA

E-mail: fabian.lange@yale.edu

\footnotetext{
* We are grateful for helpful comments from Joe Altonji, David Autor, Steffen Habermalz, Paul Oyer, Chris Taber and seminar participants at Collegio Alberto Turin, Columbia University, the 9th IZA/SOLE Transatlantic Meetings, IZA - Bonn, the 2010 SOLE meetings, University of California - Berkeley, Maastricht University, Princeton University, University of Alicante, University of British Columbia, University of California - San Diego, University of Koeln, University of Rochester, University of Southern California, University of Wisconsin, the Utah Winter Business Economics Conference 2010 and Yale University. We thank Mike Gibbs and George Baker for providing the data. Doug Norton provided able research assistance.
} 


\section{Introduction}

Understanding why wages of observationally similar workers evolve differently and why these differences increase with age are among the central questions of labor economics. Answers to these questions typically assume that either worker productivity changes heterogeneously over the life-cycle or that employers receive new information about the skills and abilities of workers. Both answers can account for two empirical regularities regarding wage residuals: the variance of wage residuals increases with experience and innovations in wage residuals have a large unpredictable component. ${ }^{1}$ Indeed, distinguishing between these alternative hypotheses is intrinsically difficult because employer learning is not observable per se, and employer expectations about worker productivity are not directly observable. Understanding the contributions of productivity evolution and employer learning to pay changes over the life cycle is the task of this paper.

A large literature tests productivity models by analyzing the second moments of wage residuals (e.g., Abowd and Card 1989, Hause 1980, MaCurdy 1982 and Baker 1997). The observation that log wage residuals have a large unpredictable component was seen as evidence against human capital models. By contrast, observing that wage growth correlates over time was seen as evidence for systematic differences in human capital accumulation. A major obstacle in this literature is the inability to separate productivity from pay using wage data alone, since wage dynamics could be driven by changes in either productivity or firm expectations.

Considerable advancements were made in the employer learning literature beginning with Farber and Gibbons (1996) and Altonji and Pierret (2001) and later Lange

\footnotetext{
${ }^{1}$ These findings are intuitive. In learning models, wages equal expected productivity conditional on the information available at any age. The variance of conditional expectations increases as the conditioning set increases, implying the same for the variance of wage residuals. Furthermore, because past wages are included in the firm's information set, wage growth will be uncorrelated over time. In productivity models, one could simply assume a stochastic evolution process which yields these patterns for productivity and therefore wages.
} 
(2007). In order to separate productivity from pay, this literature relies on the AFQT score - a correlate of productivity that may be unavailable to firms at point of entry into the labor market - available in the NLSY79. The fact that wages increasingly correlate with such variables over the life-cycle is seen as evidence for employer learning. However, one concern to this approach is that it requires the assumption that employers did not have access to the AFQT score when setting wages, even though knowledge of the test score would have been valuable, and it may have been possible to collect. Another drawback is that it cannot allow for productivity dynamics because AFQT scores reflect skill differences among individuals that existed prior to labor market entry.

In this paper, we provide new evidence on whether employer learning or changes in worker productivity drive changes in wage residuals over the life cycle. To do this, we use a 20-year unbalanced panel data set of all managerial employees in one firm, previously analyzed in Baker, Gibbs and Holmstrom (1994a and 1994b, BGHa and BGHb hereafter). ${ }^{2}$ For our purposes, these data have the crucial and as yet unexploited advantage that they contain both annual pay of workers as well as performance ratings in the form of subjective managerial assessments. The panel structure allows us to observe performance ratings that were collected prior to, contemporaneous to, and after the current period. The latter provides us with information about worker productivity that the firm was not able to exploit when setting wages. We can thus dispense with the ad-hoc assumptions on the information available to firms that were previously required in this literature. The fact that we have repeated performance ratings obtained at various points over the life-cycle allows us to estimate dynamic specifications of productivity and learning that go beyond those currently estimated

\footnotetext{
${ }^{2}$ These landmark studies provided early empirical evidence on the internal organization and pay dynamics of the firm. Their findings have inspired the well known contributions by Gibbons and Waldman (1999 and 2006) who reconcile most of the BGH findings by combining simple models of job (and later task) assignment, human-capital acquisition and learning. In addition, Gibbs (1995) describes the empirical relationship between pay, promotions and performance and DeVaro and Waldman (2007) use the data to test the Waldman (1984) promotion-as-signal hypothesis.
} 
in the literature.

To fully exploit these data, we develop a dynamic model of learning and productivity. In the model, firms set pay equal to expected productivity which they predict using noisy signals of productivity. In addition, worker productivity itself varies stochastically over time. It follows that wages vary over the life-cycle because of both firm updating and productivity evolution. The model thus nests both of the competing explanations for how wages vary over the life-cycle: evolving productivity and employer learning. Further, the nesting allows us to test the pure models against each other.

We show that the correlations of pay with performance, measured at various lags and leads, are particularly informative for distinguishing between models. For example, a pure learning model predicts that these correlations will be larger for past performance measures than for future because firms have incorporated the new noisy signals. Over time, as firm expectations become more precise and they update less on new signals, this discrepancy should fall. In contrast, the pure productivity model, which assumes full information, predicts no distinction between correlations of wages with past and future performance evaluations, per se.

In isolation, neither model can fully reproduce the moments of the data. We find evidence for employer learning in that we observe that wages are more highly correlated with past rather than future performance ratings. However, we observe this pattern even for workers at high experience levels, contradicting the pure learning model. When estimating the full model, these facts lead us to conclude that firms do learn about worker ability and that productivity evolves over time. Somewhat surprisingly, we find that the initial variance in productivity is quite small and that firms are well informed about the skills of workers at the outset of their careers. ${ }^{3}$ Over

\footnotetext{
${ }^{3}$ This finding is however consistent with Arcidiacono et al. who show that firms have more precise initial expectations about college graduates than high school graduates. Our sample of managers, reflecting highly skilled workers, should be more similar to the college graduates sample.
} 
time, productivity evolves substantially, thanks to both a predictable and a random walk component. Therefore the firm must continuously learn about a moving target, even at high experience levels.

Overall, we find that wages differ significantly from individual productivity at all experience levels. Nevertheless, the majority of the observed dispersion in wage residuals is due to variation in individual productivity. We believe that this reinterpretation of the role of learning represents a significant contribution to the empirical literature on employer learning (based on Farber and Gibbons 1996 and Altonji and Pierret 2001).

The remainder of this paper is structured as follows. Section 2 introduces the model of learning and productivity, shows how this model nests the pure learning and pure productivity models, and discusses the identification of these two models. Section 3 describes the data. Section 4 reports the estimation method and results and evaluates the fit of the model. In Section 5, we interpret the estimates and what they imply for how learning and productivity contribute to wage dynamics. Section 6 concludes the paper.

\section{A Model of Learning and Productivity}

In this section, we introduce the model that we use to organize the discussion and empirical evidence. ${ }^{4}$ We have chosen a parsimonious specification that nests two of the main models of wage dynamics, the pure employer learning model and the pure productivity model. Each model represents a distinct view point about how wages evolve over the life-cycle. The pure learning model goes back to the specification analyzed by Farber and Gibbons (1996) (see also Altonji and Pierret (2001) and Lange (2007)). This model assumes that individual heterogeneity in productivity is

\footnotetext{
${ }^{4}$ The models we analyze in this paper are special cases of a more general class of models of learning and productivity that can be analyzed using the tools developed in this paper. We present this more general class of models in the appendix.
} 
fixed across the life-cycle and that wage dynamics are driven entirely by learning on the part of employers. The pure productivity model instead assumes that employers are perfectly informed about worker productivity. Wage dynamics in this model reflect variation in productivity over the life-cycle. The nested model allows for both: productivity varies heterogeneously over the life-cycle and employers are assumed to constantly update their information about individual productivity.

\subsection{The Nested Model}

We begin by making a number of assumptions that apply not only to the models we analyze in this section, but also to the more general model developed in the appendix I. We assume that labor markets are spot markets and that information is symmetric across all employers. ${ }^{5}$ This implies that workers are paid their expected productivity in each period. Furthermore, we assume that firms know the structure of the economy and they update their expectations in a Bayesian manner. We now specify the three main components of the model: the process of productivity evolution, the information structure and the measurement issues that link the theory to our data.

\section{Productivity Evolution}

A scalar $\widetilde{Q}_{i t}$ summarizes worker productivity. Productivity varies with observed characteristics $\left(x_{i}\right)$ and experience $t$. Thus, we let $\widetilde{Q}_{i t}=Q(x, t) * Q_{i, t}$, where $Q(x, t)=$ $E\left[\widetilde{Q}_{i t} \mid x, t\right]$ and $Q_{i, t}$ is the idiosyncratic component of individual productivity. Let $q_{i t}=\log \left(Q_{i t}\right){ }^{6}$

\footnotetext{
${ }^{5} \mathrm{~A}$ large literature deviates from the assumptions of spot markets and symmetric information. For example, Gibbons and Katz (1991), Kahn (2009a),Schönberg (2007) and DeVaro and Waldman (2007) provide evidence, in a variety of settings, that employers learn asymmetrically. Further BGH (1994b), Beaudry and DiNardo (1991), Kahn (2010), and Oreopoulos et al. (2006) show that pay is in part dependent on past labor market conditions. We are enormously sympathetic to this literature, especially since one of us has contributed to it. However, it would be intractible to include features of these models in our paper. What is important for us is despite evidence of the existence of these market imperfections, there is also substantial evidence that firms are constrained by market forces when setting pay policies. For example, BGH (1994b) find that the firm analyzed here does not fully shelter pay from market fluctuations.

${ }^{6}$ By construction $q_{i t}$ is mean zero and uncorrelated with the controls x. From now on, we will
} 
The difference equation (1) provides a simple, yet flexible way of representing the evolution of individual log productivity $q_{i t}$ :

$$
q_{i t}=q_{i t-1}+\kappa_{i}+\varepsilon_{i t}^{r}
$$

We assume $\kappa_{i} \sim N\left(0, \sigma_{\kappa}^{2}\right)$ and $\varepsilon_{i t}^{r} \sim N\left(0, \sigma_{r}^{2}\right)$ and that the $\varepsilon_{i t}^{r}$ are uncorrelated over time and with $\kappa_{i}$. We initialize this difference equation in period 0 with a draw of $q_{i 0}$, drawn from a normal distribution $N\left(0, \sigma_{q}^{2}\right)$. This draw is independent of $\kappa_{i}{ }^{7}$

According to equation (1), the log of individual productivity, $q_{i t}$, evolves following an experience profile with three sources of heterogeneity. The heterogeneity in $q_{i 0}$ captures differences in initial ability. The heterogeneity in the drift parameter $\kappa_{i}$ implies persistent differences in the intensity with which individuals accumulate human capital over the life-cycle. ${ }^{8}$ Finally, the innovations $\varepsilon_{i t}^{r}$ represent time-variation in individual productivity that are not predictable. The i.i.d. assumption on the $\varepsilon_{i t}^{r}$ implies that the variation in these innovations does not decline with experience and that individual productivity diverges even for relatively experienced workers.

There are various possibilities for why worker productivity might evolve randomly over time. It is for instance plausible that at least a subset of workers is subject to health shocks that affect performance. A more intriguing possibility is that experience affects the tasks individuals are required to perform. If productivity on past tasks does not perfectly predict productivity on future tasks, then worker productivity would indeed be subject to unpredictable variation as individuals gain experience (Gibbons and Waldman 2006).

\section{Information Structure}

suppress the dependence on $\mathrm{x}$. We generally follow the notational convention that upper case and lower case letters refer to variables measured in levels and logs, respectively.

${ }^{7}$ We adopt the convention that period 0 is a period prior to the first period the individual spends in the labor market.

${ }^{8}$ Persistent differences in intensity would arise, for example, if individuals differ in either their preferences or ability to invest (Becker (1964), Ben-Porath (1967)). 
The flow of information to employers is modeled using three different signals. Information firms hold about worker productivity at the beginning of their career is embodied in an initial signal $z_{i 0}$. As individuals spend time in the labor market, firms observe two signals in each time period: $\left\{p_{i t}, z_{i t}\right\}_{t=1}^{T}$. The signals $z_{i 0}$ and $\left\{z_{i t}\right\}_{t=1}^{T}$ are not observed in the data available to researchers. The only signal that is (partially) contained in our data is $p_{i t} .{ }^{9}$ We assume that all three signals are normally distributed around $q_{i}$ and therefore have $z_{i 0}=q_{i}+\varepsilon_{i 0}, p_{i t}=q_{i}+\varepsilon_{i t}^{p}, z_{i t}=q_{i}+\varepsilon_{i t}^{z}$ where $\varepsilon_{i 0} \sim N\left(0, \sigma_{0}^{2}\right), \varepsilon_{i t}^{p} \sim N\left(0, \sigma_{p}^{2}\right)$, and $\varepsilon_{i t}^{z \sim} N\left(0, \sigma_{z}^{2}\right)$. The normality assumptions ensure great parsimony for the model, allowing us to analyze the learning process using the tools of Kalman filtering. Without loss of generality, we impose that $\operatorname{cov}\left(\varepsilon_{i t}^{z}, \varepsilon_{i t}^{p}\right)=$ $0 .{ }^{10}$

Based on the spot market assumption made above, wages will equal expected productivity conditional on all signals the firm has observed up to that point.

\section{Measurement Issues}

Two measurement issues arise when we try to map the above model onto the particular data we consider. First, and quite standard, we allow for measurement error in wages:

$$
W_{i, t}=W_{i, t}^{*} \Omega_{i, t}
$$

where $W_{i t}$ is the observed wage, $W_{i t}^{*}$ is the wage measured without error and $\Omega_{i t}$ represents the measurement error. Taking logs we get

$$
w_{i t}=w_{i t}^{*}+w_{i t}
$$

We assume that $\omega_{i t}$ is classical measurement error with $\omega_{i t} \sim N\left(0, \sigma_{\omega}^{2}\right)$.

The second issue arises from the fact that our observed productivity signals, $p_{i t}$,

\footnotetext{
${ }^{9}$ In the data section, we describe more precisely the information we have on $p_{i t}$.

${ }^{10}$ The information in correlated normal signals is identical to the information contained in orthogonalized signals. The correlations between $p_{i t}$ and wages are therefore identical, regardless of whether the firm observes a correlated signal or an uncorrelated signal.
} 
are subjective managerial performance evaluations (described in more detail below). As we estimated the model, we found that these performance ratings were very highly correlated across short time horizons. We believe this pattern arises from temporary stickiness in performance evaluations and does not reflect true productivity evolution. Such persistence could occur, for example, if workers are temporarily matched with the same manager for several periods who may then give similar ratings. Or, managers may be reluctant to give ratings that deviate too far from past performance, if they anticipate the unpleasantness of dealing with worker complaints or needing to provide extra justification. We model this effect by assuming that the $\varepsilon_{i t}^{p}$ evolve according to equation (4)

$$
\varepsilon_{i t+1}^{p}=\rho \varepsilon_{i t}^{p}+u_{i t+1}
$$

where the initial noise is $\varepsilon_{i 1}^{p}=0$ and $u_{i t} \sim N\left(0, \sigma_{u}^{2}\right)$. The parameter $\rho$ governs the degree of persistence in manager ratings and will be estimated. Other than this, we assume that signals reflect new information, i.e., the signal errors $\left(\varepsilon_{i 0}, \varepsilon_{i t}^{z}, u_{i t}\right)$ are uncorrelated across time. ${ }^{11}$

\section{Summary}

The model described above is governed by only 8 parameters: $\left(\sigma_{q}^{2}, \sigma_{r}^{2}, \sigma_{0}^{2}, \sigma_{u}^{2}, \sigma_{\omega}^{2}, \sigma_{\kappa}^{2}, \rho, \sigma_{z}^{2}\right)$. This parsimony makes quite transparent what features of the data drive the parameter estimates. At the same time the model has the advantage of nesting the two interpretations of wage dynamics that are the object of our inquiry: employer learning and productivity dynamics. By imposing the appropriate restrictions on these

\footnotetext{
${ }^{11} \mathrm{~A}$ different modeling assumption would be to put the auto-regressive component, $\rho$, directly into the productivity evolution equation. This would yield some auto-correlation in performance measures. However, this assumption violates several of the observed patterns in our data, which we describe below. Specifically, because $p_{i t}$ contains noise terms, $\varepsilon_{i t}^{p}$, the AR-1 process in observed performance would exhibit less persistence than the AR-1 process in true productivity. In order to generate the relatively large auto-correlations between $p_{i t}$ and $p_{i t-1}$ (we show below that these are on the order of 0.6 ), we would need the signal noise in $\varepsilon_{i t}^{p}$ to be very small. But, if the $\varepsilon_{i t}^{p}$ were very precise, then we would necessarily require wages and performance signals to be very highly correlated, contradicting the findings in the data.
} 
parameters, we can recover either the pure learning or the pure productivity model. The restriction $\sigma_{\kappa}^{2}=\sigma_{r}^{2}=0$ eliminates any heterogenous dynamics in productivity and delivers the pure learning model. By contrast, the restriction $\sigma_{0}^{2}=\sigma_{z}^{2}=0$ implies that the firm is perfectly informed at any stage of the life-cycle and thus delivers the pure productivity model.

\subsection{Implications and Identification}

We now derive several intuitive implications from the model which help illustrate how we can identify distinctions between the employer learning and productivity models. In appendix II, we provide a more formal discussion of how the parameters in the model can be identified using the second moments of wages and performance ratings.

First, it is worth pointing out that wage data alone would not be sufficient for our exercise of distinguishing between learning and productivity models as the main drivers of wage dynamics. Indeed, we could always specify a full information model with productivity evolution that would replicate the second moments of wages. For example, observing that log wages follow a random walk has been taken as evidence of employer learning (Farber and Gibbons 1996). However, this pattern would also be obtained under a full information productivity process that evolves as a random walk. Therefore, identifying joint models of learning and productivity dynamics using wage data alone will be fundamentally dependent on the functional form restrictions that one is willing to impose on the productivity process. Access to productivity correlates such as performance ratings adds a different source of information that helps resolve this identification problem.

Especially helpful is the co-variation in pay with performance across experience. To illustrate, we consider what the pure learning model implies for how pay covaries with past performance measures as opposed to future performance measures. To simplify the discussion assume, for now, that performance ratings are uncorrelated 
over time $(\rho=0)$ and that there is no measurement error in wages $\left(\sigma_{\omega}^{2}=0\right)$. Then, an individual's wage will be given by the following expression:

$$
w_{i t}=E\left[q_{i} \mid I^{t}\right]=\chi_{t}+\left(1-K_{t-1}\right) * E\left[q_{i} \mid z_{i 0}\right]+K_{t-1} \frac{1}{t-1} \sum_{j=1}^{t-1} \phi_{i j}
$$

where $\quad \phi_{i t}=(1-\phi) p_{i t}+\phi z_{i t}$

$$
K_{t}=\frac{t \sigma_{q}^{2}}{t \sigma_{q}^{2}+\sigma_{\phi}^{2}}
$$

This expression contains both a component $\chi_{t}$ that is common across individuals and a component that depends on the signals the firm obtains. ${ }^{12}$ In each period, we combine the two signals $z_{i t}$ and $p_{i t}$ into a single scalar $\phi_{i t}$ that represents a sufficient statistic for the information obtained in period $t$. The weight $\phi$ depends on the variance of the signal noise in both signals. ${ }^{13}$

From equations (5)-(7), it is easy to derive the covariances between pay and performance measures across time:

$$
\operatorname{cov}\left(w_{i t}, p_{i \tau}\right)=\left\{\begin{array}{cc}
K_{t-1}\left(\sigma_{q}^{2}+\frac{1-\phi}{t-1} \sigma_{p}^{2}\right) & \tau<t \\
K_{t-1} \sigma_{q}^{2} & \tau \geq t
\end{array}\right\}
$$

Equation (8) encapsulates three of the features implied by the pure learning model that are particular noteworthy.

First, for $\tau>t$, the $\operatorname{cov}\left(w_{i t}, p_{i \tau}\right)$ increases with $t$ as $K_{t-1}$, the weight placed on the stream of performance measures, grows. Intuitively, as the firm learns, the wage becomes increasingly correlated with underlying productivity and therefore will also correlate more with any signal of productivity, i.e., future performance ratings. Second, $\operatorname{cov}\left(w_{i t}, p_{i \tau}\right)$ is larger for performance measures that occurred before the wage

\footnotetext{
${ }^{12}$ The time effects $\chi_{t}$ capture both the common variation in $\log$ productivity over time and also how the variance of the prediction error varies with experience. A convenient feature of the normal learning model is that the variance of the prediction error does not depend on the observed signals and is instead common across all individuals with the same level of experience.

${ }^{13}$ The exact expressions for $\phi$ and $\sigma_{\phi}^{2}$, the variance of the scalar signal $\sigma_{\phi}^{2}$, are known, but not of particular interest at this point.
} 
was set $(\tau<t)$, than for performance measures that were not yet observed when the wage was set $(\tau \geq t)$. This is because current pay incorporates the realizations of $\varepsilon^{p}$ from previously observed performance measures, but not from future performance measures. Therefore, under the learning model, the relationship between $\operatorname{cov}\left(w_{i t}, p_{i \tau}\right)$ and $\tau$ will be a step function. The size of the step can be obtained by differencing the two expressions in equation (8) and is equal to $K_{t-1} \frac{1-\phi}{t-1} \sigma_{p}^{2}$. This yields the third prediction that the size of the step decreases in $t$. Intuitively, firms' expectations are based on substantially more productivity ratings when $t$ is large and they therefore put less weight on any given signal $p_{i t}$ when setting wages. ${ }^{14}$

Thus, the learning model implies a discontinuity at the present when we compare how pay in any period correlates with past and future performance ratings. For learning models, the distinction between the past and the future is fundamental, because it separates observed and unobserved information, generating the discontinuity in correlations. By contrast, the pure productivity model treats the past and the future symmetrically, since the firm has full knowledge of productivity when setting pay. It therefore could not generate the step function described above.

\section{Data}

\subsection{General description}

This paper analyzes data first used by BGHa and BGHb in their canonical studies of the internal organization of the firm. The data consist of personnel records for all managerial employees of a medium-sized, US-based firm in the service sector from 1969-1988. We have annual pay and performance measures, as well as some demo-

\footnotetext{
${ }^{14}$ While correlations of wages with future performance rise as workers gain experience, this does not happen for correlations with past performance. In a learning model, though wages increasingly correlate with true productivity, that effect is offset by the fact that firms use any given productivity measure less for older workers since their expectations have become more precise.
} 
graphics and a constructed measure of job level (see BGHa for more detail). The original sample contains 16,133 employees. Of these, we restrict attention to the 9,391 employees with a non-missing education variable who can be observed with a wage or performance measure between the ages of 25 and 54 and at least one more wage or performance measure. ${ }^{15}$

Because we have data on only one firm, we may suffer from several selection problems. We are concerned that attrition from the sample is non-random, since nonrandom turnover could bias our results. In appendix III, we estimate a selection corrected version of our model that corrects for attrition based on observables and find that our results are unchanged when we estimate this version of the model.

Summary statistics are reported in table 1 . The majority of managers are white males with at least a college degree. Annual salary averages almost $\$ 54,000$ in cpiadjusted 1988 dollars and measures base pay. ${ }^{16}$ The performance ratings range from 1 to 4 , with higher rating reflecting better performance. ${ }^{17}$ From table 1, we see the average rating is a little over a 3 and the distribution is top heavy, with more than $75 \%$ of workers receiving one of the top two ratings. ${ }^{18}$

\section{Table 1: Summary Statistics}

Figure 1 plots log pay and performance residuals by age, with solid and dashed

\footnotetext{
${ }^{15}$ Age 25 might be considered slightly old to begin the processes of employer learning and postschool skill accumulation for most education groups. However, our sample consists of workers who have already been promoted to the level of manager. As we have no way of learning about their labor market experiences before they enter this sample, we start at the earliest age which still yields a decent sample size. This is also why we extend the anaylsis to age 54. From now on, we adopt the convention that age 25 is the first year of experience.

${ }^{16}$ We have information on bonus pay for some years (1981-1988) but do not include it in the analysis to maintain consistency in our data across years. In these years, $22 \%$ of workers receive a bonus and, conditional on receiving a bonus, the amount is on average $12 \%$ of base salary.

${ }^{17}$ We inverted and recoded the original measures, which ranged from 1 to 5 , combining the worst two ratings since almost nobody receives the worst.

${ }^{18}$ This distribution of performance ratings is similar to those found in Medoff and Abraham (1980 and 1981) and Murphy (1991) in their studies of performance ratings across various industries and firms.
} 
lines, respectively. ${ }^{19}$ The solid line shows that the earnings-experience profile is rising and concave, reflecting typical life-cycle patterns. The dashed line reveals, somewhat surprisingly, that average performance falls with age. This is unexpected if we think part of the explanation for the rising age-earnings profile is that workers are accumulating more skills. However, this finding is common in the literature, exhibited in Medoff and Abraham $(1980,1981)$ for example. They interpret subjective performance measures as relative ranks within a comparison group. Once ratings are relative, we could rationalize almost any age-performance profile.

Figure 1: Log Wages and Performance by Age

In our analysis, we follow the common practice in the literature to treat the performance measures as relative. That is, we interpret observed performance, $\tilde{p}_{i t}$, as arising from a latent signal on individual productivity, $p_{i t}$, according to the mapping in equation (9)

$$
\tilde{p}_{i t}=\sum_{k=1}^{K-1} \mathbf{1}\left(p_{i t} \geq c_{k t}\right)
$$

A worker is assigned the ranking $\tilde{p}_{i t}=k$ if his or her latent productivity signals falls between the two thresholds, $c_{k-1 t}$ and $c_{k t}$. We allow these thresholds to differ across age groups, thus incorporating the assumption that ratings are relative to individuals of the same age. ${ }^{20}$ The structure assumed in section 2 yields that the latent signal, $p_{i t}$, is normally distributed. We can therefore estimate correlations of $p_{i t}$ with other normally distributed variables (such as log wage residuals and lagged performance) using maximum likelihood methods. Of course, since the observed

\footnotetext{
${ }^{19}$ Both variables are residualized on the following set of variables, all interacted with education group (high school, some college, exactly college, advanced degree): gender, race and year dummies and gender- and race-specific time trends.

${ }^{20}$ Age may not capture the exact reference group for a worker. We could easily include demographics, such as race, gender and education, in forming these groups, though we have not done so here. However, our results are robust to allowing performance to be relative to other workers in one's entry cohort or job level.
} 
performance ratings are categorical, we cannot identify the variance of $p_{i t}$.

It is worth noting that, though subjective performance measures are less desirable for this exercise, previous literature has shown that when both objective and subjective performance measures are available, they are significantly positively correlated (Jacob and Lefgren 2008 and survey by Bommer et al. 1995). Further, Gibbs (1995) shows that these performance ratings do contain meaningful information. For example, high performance ratings are correlated with higher raises and bonuses, and increase the probability of promotions. Lastly, we feel that both allowing for an auto-regressive component to performance ratings and treating them as categorical variables reflecting relative ranks are important statistical measures which help us extract the signal in what some may argue are particularly noisy variables.

\subsection{Moments for estimation}

Our model outlined above generates implications about the second moments of wages and performance across different experience levels. Here we present the empirical analogs which we use to estimate our model. In principle, we could match correlations in wages and performance ratings across all 30 age levels, 25-54. Instead, we simplify the estimation and exposition by constructing a set of 68 moments, that we think are particularly informative for distinguishing learning and productivity models. These moments are displayed in figures $2 \mathrm{a}$ and $2 \mathrm{~b}$ with $95 \%$ bootstrapped confidence intervals. $^{21}$

Figures 2a and 2b: Moments and 95\% CI

Panel $\mathrm{A}$ in figure 2a shows the variance in log wage residuals for six 5-year experience groups ranging from 1-5 to 26-30 years. The variance in pay around the

\footnotetext{
${ }^{21}$ In constructing these moments, we first residualize all pay and performance measures by the following variables all interacted with education group: gender, race age and year dummies, genderand race-specific time trends as well as gender and race interacted with a quadratic in age. We then take average correlations and variances across the specified set of experience years weighted by the number of individuals for which we observe that moment.
} 
age profile is substantial and increases almost linearly with age. It is only after 25 years of experience that the growth in the variance of pay slows. ${ }^{22}$ Understanding this variation and its increase over the life-cycle is the primary task of this paper.

Panels B and C in figure 2a show auto-correlations in performance and pay residuals, respectively, for up to 6 lags and for two experience groups: experience 1-15 shown with solid dots and 16-30 with hollow dots. For both pay and performance, the more experienced group exhibits higher auto-correlations which fall the further away in time the observation was. In panel $\mathrm{B}$, the performance auto-correlations exhibit some nonlinear decay across lags. As discussed above, we fit this stickiness in performance ratings with the parameter, $\rho$.

Panel D in figure 2a shows correlations in pay changes for up to 9 lags and for the same two experience groups. As has been observed in MaCurdy (1982), Baker (1997) and many other papers that investigate the 2 nd moment properties of log wages, the autocorrelation in wage growth identifies permanent heterogeneity in productivity growth (when $w_{i t}=q_{i t}$, as in the pure productivity model). In contrast, a pure learning model could not yield this implication because each wage innovation reflects new information obtained by the firm in that period. ${ }^{23}$ Here we clearly have evidence consistent with productivity evolution since all correlations in pay changes are sizeable and statistically distinguishable from zero. ${ }^{24}$

Panel D also exhibits a sharp decline in correlations across lags, which stabilizes at the 4th lag and remains fairly constant through the 9th lag. We believe this decline may be evidence of some stickiness in wage growth. Given our spot market assumption and the current structure of our productivity process we cannot fit this decline. Instead, we fit only the 4th through 9th lags, since including the first three

\footnotetext{
${ }^{22}$ It is worth noting that these variances are quite a bit lower than one would observe in a crosssection (for example, the variance in log earnings residuals is 0.04 in the first experience bucket). This is because we are already restricting attention to workers in the same firm and occupation.

${ }^{23}$ Farber and Gibbons (1996) propose testing the pure learning model using exactly this absence of autocorrelation in wage growth.

${ }^{24} \mathrm{BGHb}$ also obtained this result and took it as evidence of hetergeneous growth in productivity.
} 
causes problems in the estimation. ${ }^{25}$

Lastly, we focus on figure $2 \mathrm{~b}$, which gives correlations between current pay and past, current and future performance measures for up to 6 lags and leads, again across the two experience groups. We pay particular attention to these moments throughout the paper because we believe they represent the major innovation to the previous literature . In section 2, we argued that these correlations are informative about employer learning. In particular, the pure learning model yields three testable implications: correlations of wages with future performance measures rise with experience; correlations of wages with past performance measures decline with experience; and the relationship between $\operatorname{cov}\left(w_{i t}, p_{i \tau}\right)$ and $\tau$ will be a step function. A corollary of these three implications is that the size of the step should decline with experience.

Figure $2 \mathrm{~b}$ provides evidence consistent with two of the predictions. Correlations for future performance measures are larger for the higher experience group, suggesting firm expectations approach true worker productivity over time. Also, we indeed see an asymmetry in correlations of wages with past, relative to future performance evaluations. For example, for young workers, the correlation of pay with one lag in performance is 0.015 larger than that with one lead in performance. This and the comparison for two periods out are statistically significant at the $5 \%$ level, while the comparison for three periods out is statistically significant at the $10 \%$ level. However, the step size does not appear to fall with experience, contradicting the third prediction. Indeed the correlations of pay with past performance are on average 0.06 larger than those of future performance. All differences at similar time distances are statistically significant at the $1 \%$ level.

Thus we see reduced form evidence consistent with both heterogenous productivity growth and employer learning. However, firms continue to exhibit patterns of learning

\footnotetext{
${ }^{25}$ We fit up to 9 lags here because we wanted to gain a better sense of the decay process past the first 3 lags. These long run correlations are of particular interest because they cannot be generated by any temporary correlations in wage growth.
} 
even for workers at high experience levels, suggesting that the pure learning model alone will not be able to fit the data.

\section{Estimation}

In Section 2 we developed a model of learning and productivity that represents a special case of the more general model described in Appendix I. In this appendix, we also describe how one can use linear state space methods to derive the moments of these more general models. Applying these methods to our specific case, we can obtain the implied second moment matrices for wages and performance ratings. These results allow us to implement method of moments, matching to the empirical moments described above, to estimate the parameters of our model.

Table 2 displays our parameter estimates for the three models which we obtain via method of moments with equal weights on all moments. Standard errors, obtained by bootstrapping with 500 repetitions, are shown in parentheses. ${ }^{26}$ We now discuss the fit of each model. As we have mentioned, we pay particular attention to the correlations between pay and performance and various lags and leads. These results, discussed below, are summarized for all 3 models in figure 3 .

Table 2: Parameter Estimates.

Figure 3: Correlations of Pay and Performance

\section{The Pure Learning Model}

Panel B of figure 3 and figure 4 summarize the results of the pure learning model,

\footnotetext{
${ }^{26}$ The exact bootstrapping procedure is as follows. We draw the sample randomly, with replacement and generate the bootstrapped moments. We then estimate the parameters to match these moments, taking as starting values the true parameters values shown in table 2 . We do not search across starting values to find the global minimum for each of the 500 samples. However, in each bootstrap, we go through four optimization routines (alternating between Newton-Rapson and the simplex method), which should ensure we have found the global minimum.
} 
contrasting the empirical moments with the predictions based on the estimated parameters for the pure learning model (restricting $\sigma_{\kappa}^{2}=0$ and $\sigma_{r}^{2}=0$ ). The predicted moments are shown using solid lines for younger workers and dashed lines for older workers.

We find that the learning model does succeed in a number of ways. Using a small set of parameters, it matches the variance of wages across experience levels. It also matches the approximate levels of the auto-correlations in wages by experience, though not the decline across lags. It matches the decay across lags in the auto-correlations of performance measures, thanks to the parameter $\rho$, but not the differences across experience. The model, by construction, predicts that wages follow a random walk and therefore the learning model is not able to match any of the long-run positive correlations in pay growth that we observe in the data and report in panel $\mathrm{D}$ of figure 4.

Figure 4: Results for the pure learning model.

However, as is evident in Figure 3, panel B, the pure learning model does not fit the correlations between pay and performance ratings that we believe to be the most important new empirical evidence we add to the literature. The data show that the correlations of pay and performance are generally increasing with experience, resulting in a sizeable asymmetry between correlations of wages with past and future performance measures even at high experience levels. In contrast, the fitted learning model predicts a cross-over pattern. For young workers, firms rely heavily on past performance measures, since current expectations are imprecise. This should result in wages that are more highly correlated with past performance for younger, relative to older, workers. The model predicts the reverse for the correlation of current wage with future performance. Because firm expectations become more precise, wages of older workers should approach true worker productivity and become increasingly correlated 
with future performance.

This failure reflects general features of pure learning models and, in our view, is not a result of any particular distributional assumptions. Overall, we therefore find significant evidence against the pure learning model.

\section{The Pure Productivity model}

Figure 3, panel $\mathrm{C}$ and figure 5 show the fit of the pure productivity model.

Figure 5: Results for the pure productivity model

Along a number of dimensions, the pure productivity model does better than the pure learning model. First, because the variance of the heterogeneous growth term $\kappa_{i}$ reported in table 2 is non-zero, the pure productivity model generates long run correlations in wage changes that are positive, though smaller in magnitude than the observed moments. The pure productivity model also fits both the auto-correlations in pay and performance, better than the learning model did. Allowing productivity to vary yields stronger declines in auto-correlations across lags and experience groups that the learning model could not predict. However, this model does poorly in fitting the experience profile of variance of log pay. Growth rate heterogeneity implies that the variance rises in the square of experience, producing the convex pattern fitted by the model.

Turning to our main set of moments (figure 3 panel C), the evidence regarding the pure productivity model is mixed. A success for the model is that it manages to fit the approximate levels of correlations across experience groups. Intuitively, these correlations increase with experience because, as the variance in productivity increases with experience, the common component in performance ratings and wages becomes more important, relative to the noise in the performance ratings. Further, $\kappa_{i}$ has a larger impact on performance further into the future, increasing those correlations

with any given wage. This is the same reason why the correlations of pay with future 
performance rise with the number of leads, another failure of the model. Finally, as discussed above, the pure productivity model fails to match the asymmetry in the correlations between pay and past, compared to future, performance.

\section{The Nested Model}

Finally, we consider how the parameter estimates and fit of the nested model compare with those of the pure learning and productivity models. Results from the nested model are shown in figure 6 and panel D of figure 3.

Figure 6: Results for the combined model

Overall, our estimates emphasize that it is important to account for both learning and productivity growth in explaining the data. Indeed, the nested model can fit the correlations between pay and performance, both the levels across experience and the asymmetry across lags, though it admittedly has trouble fitting the decline after about four leads into the future. In addition, because of imperfect information, productivity innovations are not immediately incorporated into pay. Therefore, the model is also able to fit higher correlations in pay growth, resulting from a larger $\kappa_{i}$, while keeping only a small convexity in the variance in log wages across experience.

In fact, the nested model attributes a larger role to persistent differences in productivity growth, $\kappa_{i}$, and less of a role to random innovations in productivity, $\varepsilon_{i}^{r}$. An increase in $\kappa$ of one standard deviation corresponds to $45 \%$ extra productivity growth over our time horizon in the nested model, and $35 \%$ in the pure productivity model. Over the same time period, a standard deviation of the sum of random walk components is about $12 \%$ and $25 \%$ for the nested and pure productivity models, respectively.

Turning to the estimates of learning parameters, we find that the variance in all of the signals is much greater for the pure learning model than the nested model. The 
variance of the initial signal $\left(\sigma_{0}^{2}\right)$ is about four times larger in the pure learning model and the variance in the the two dynamic signals $\left(\sigma_{z}^{2}, \sigma_{u}^{2}\right)$ is likewise substantially large. This is likely due to the fact that in order to match the evidence for learning even at higher experience levels, the pure learning model needs to impose relatively slow learning. In contrast, the nested model can fit learning throughout the life-cycle by introducing additional variation in productivity.

Statistically, we reject the pure learning and pure productivity models in favor of the nested model. We reject the restrictions of the pure productivity model $\left(\sigma_{0}^{2}=\sigma_{z}^{2}=0\right)$ against the unrestricted model at a $97.5 \%$ significance level (the $\chi^{2}$ statistic with two degrees of freedom is 7.51). The restrictions of the pure learning model $\left(\sigma_{\kappa}^{2}=\sigma_{r}^{2}=0\right)$ are rejected at any reasonable significance level with a $\chi^{2}$ of 487 . Overall, we thus find support for a model that combines elements of learning with heterogenous changes in productivity over the life-cycle.

\section{Interpretation}

In this section, we interpret the magnitudes of the estimates of the nested model and discuss alternative explanations. In particular, we are interested in how far productivity and wages can deviate from each other because firms are imperfectly informed and how our estimates relate to the literature on the speed of employer learning (Lange 2007). This analysis informs us about our initial question of whether wage dynamics are primarily driven by the evolution of individual productivity or by learning. It is also informative for the incentives faced by employers to invest into discovering worker productivity.

\section{Productivity and Wage Variance of the Life-Cycle}

Figure 7 plots the variances in productivity, wages and expectation error as a 
function of experience, implied by the parameters from the nested model.

Figure7: Variances in productivity, wages and expectation error, by experience

The top line shows the variance in log productivity with the variance of log wages just below. It becomes clear that both the shape and magnitude of the variance of log wages are inherited from the shape and variance of productivity. The relatively small difference in size between the variances of wages and productivity is seen, even at 30 years of experience, were variances of productivity and log wages are 0.174 and 0.154 , respectively. The difference is accounted for by the variance of the firm's error in expectations around worker productivity. At young experience levels, this variance declines as firms learn about initial productivity, $q_{i 0}$, and the persistent component of productivity growth, $\kappa_{i}$. Subsequently, the variance stabilizes at a fairly low and constant level around 0.022, reflecting that firms must continue to learn about the random walk in productivity. Thus, to understand why wages diverge over the life-cycle means first and foremost understanding why productivity evolves heterogeneously over the life-cycle.

While it might therefore seem that imperfect learning is of small consequence, since the variance of the expectation error is relatively small, we would disagree. The variance of the expectation error of about 0.022 and the fact that this variance is relatively stable over the life-cycle implies that on average, wages and productivity deviate by about $10 \%$ of annual productivity for most of the life-cycle. That is, firms make sizeable errors when estimating individual productivity and face substantial incentives to identify the more productive workers. Such a difference between wages and productivity and the fact that they persist late into individual careers make it plausible that worker turnover and human resource policies are substantially shaped by learning. 


\section{The Speed of Learning}

Our estimates also allow us to examine how rapidly firms learn about any differences in productivity that exist at the beginning of the worker's career, an exercise first performed in Lange (2007). ${ }^{27}$ He finds that initial expectation errors decline by about $50 \%$ in the first 3 years and that only $25 \%$ of the initial expectation error remains after 8 years. The parameter estimates obtained in this paper imply that expectation errors about productivity differences existing at the beginning of individual careers decline by about one third within 3 years and about $70 \%$ within 8 years. Thus, our esimates about the speed of learning about initial productivity differences are strikingly consistent with those of Lange, despite the differences in methodologies. ${ }^{28}$

\subsection{Alternative Theories linking Pay and Performance}

We have concluded above that productivity evolves heterogeneously throughout the life-cycle and firms continue to learn about this moving target. The main piece of evidence for this is the fact that past performance still correlates more highly with pay than does future performance, even at high experience levels. However, if past performance matters more for older workers, either because of pay for performance or because these measures contain a more precise signal, then we might obtain this same result. We discuss each of these in turn.

It is possible that performance evaluations become more precise as workers age

\footnotetext{
${ }^{27}$ Lange (2007) builds on the empirical strategy proposed first by Farber and Gibbons (1996) and developed by Altonji and Pierret (2001), using data on the AFQT from the NLSY 1979, to estimate how quickly firms learn about heterogeneity in worker productivity. He argues that this speed of employer learning is crucial for understanding how relevant signaling motives are in schooling decisions, because if firms learn rapidly about worker productivity, then workers have little reason to signal their productivity by taking costly actions such as acquiring schooling.

${ }^{28}$ Firms learn about 2 productivity states, $\kappa_{i}$ and $q_{i t}$. This imparts some complicated dynamics into the speed of learning, which does not allow us to summarize the speed of learning in a single parameter, as in Lange (2007). The dynamics in fact generate overshooting, such that initial productivity differences in $q_{0 i}$ will have a more than one-for-one impact on log wages for part of the individuals life-cycle.
} 
and the firm learn better how to evaluate them. This would explain why firms still update on worker productivity, for a time, at high experience levels. However, it would not explain why firms continue to update at all points along the life-cycle - recall, the difference between the correlation of pay with lags of performance, compared to leads of performance is always positive and statistically significant for the older group. Even if the variance in the productivity signal falls with age, firms should eventually stop updating, and we do not see that.

Alternatively, one might be worried about direct pay for performance. If firms directly incorporate past performance into pay, we would see larger correlations for lagged performance and wages, relative to those of future performance. Further, as workers age and are promoted, the scopes of their jobs might broaden and firms might want to strengthen the incentive. If this were the case, we should see a spike at one lag of performance (or possibly the past few performance measures). We might also see a larger spike for the high experience group. However, we do not see these patterns. We see instead that all past performance measures have roughly the same correlation with current pay ( around 0.28 for young workers and almost 0.40 for old workers). This is inconsistent with a direct pay for performance scheme. ${ }^{29}$

However, consider a deferred form of incentive pay. If the firm is operating under a tournament model (a la Lazear and Rosen 1981) where workers are compensated for their past effort upon being promoted later in life. This would result in higher correlations between pay and past performance for older workers. Correlations of pay and future performance measures could still be larger for older workers because of learning. Indeed we cannot distinguish this model from our model of productivity evolution. To do so, we would need more information on the structure of pay setting and promotions from the firm. Lacking such information in this data-set, we are forced

\footnotetext{
${ }^{29}$ It is worth pointing out that had we incorporated bonuses into our pay day, this might be different. We have not done so because we cannot get consistent bonus measures throughout the sample. However, it also means that our current measure of pay probably does not include direct incentives.
} 
to simply note this identification problem with the hope that in the future, better and more comprehensive human resource data will permit progress in distinguishing alternative explanations from the productivity and learning based model analyzed in this paper.

\section{Conclusion}

In this paper, we provide new evidence on employer learning and productivity evolution by exploiting performance evaluations, along with pay data, from a panel of workers in a single firm. We derive a nested model and show how we can uncover both the learning and productivity parameters by matching moments in the data. We find that problems of accurately predicting productivity are important for employers and that average expectation errors are large at all stages of individuals careers. However, we do not find evidence that the wage dynamics overall are driven primarily by the learning process. Instead, our model suggests that random variation in productivity drives most of the observed increase in the variance of wages over the life-cycle. We believe these findings represent a significant reinterpretation of the employer learning literature.

An important caveat to our conclusion is that we are only able to study one firm and further, only one occupation (broadly defined). Our finding that firms have quite precise expectations over worker ability at the beginning of the worker's career could be explained by the fact that these workers have already been promoted to manager. Thus the market probably had opportunities to learn about these workers, before they entered out sample. In the future, we hope to analyze other data sets containing pay and performance measures to establish the generalizability of these findings.

Seemingly contradictory to most models of human capital accumulation (Becker 1964, Ben-Porath 1967), we find that a significant component of productivity evolves 
unpredictably throughout the life cycle. One explanation for this finding is that workers are assigned to different tasks throughout the life cycle and performance on past tasks does not predict performance on future tasks. This interpretation suggests that firms shift workers into job levels and tasks with little ability to predict worker success there.

\section{References}

[1] Abowd, J. and D. Card (1989): "On the Covariance Structure of Earnings and Hours Changes," Econometrica, 57(2): 411-455.

[2] Altonji, J.G. and C.R. Pierret (2001): "Employer Learning and Statistical Discrimination," Quarterly Journal of Economics, 113:79-119.

[3] Arcidiacono, P., P. Bayer, and A. Hizmo (2010) "Beyond Signaling and Human Capital: Education and the Revelation of Ability" forthcoming, AEJ: Applied Microeconomics.

[4] Baker, G., M. Gibbs and B. Holmstrom (1994a): "The Internal Economics of the Firm: Evidence from Personnel Data," Quarterly Journal of Economics, CIX: 921-955.

[5] Baker, G., M. Gibbs and B. Holmstrom (1994b): "The Internal Economics of the Firm: Evidence from Personnel Data," Quarterly Journal of Economics, CIX: 881-919.

[6] Baker, M. (1997): "Growth-Rate Heterogeneity and the Covariance Structure of Life-Cycle Earnings," Journal of Labor Economics, 15: 338-375. 
[7] Beaudry, P. and J. DiNardo (1991): "The Effect of Implicit Contracts on the Movement of Wages over the Business Cycle: Evidence from Microdata," Journal of Political Economy, XCIX: 665-688.

[8] Becker, G. (1964): Human Capital, New York, NY: NBER.

[9] Ben-Porath, Y.(1967): "The Production of Human Capital and the Life Cycle of Earnings," Journal of Political Economy, LXXV: 352-365.

[10] Bommer, W., J. Johnson, G. Rich, P. Podsakoff and S. Mackenzie (1995): "On the Interchangeability of Objective and Subjective Measures of Employee Performance: A Meta-Analysis," Personnel Psychology, Vol 48: 587-605.

[11] DeVaro, J. and M. Waldman (2007): "The Signaling Role of Promotions: Further Theory and Empirical Evidence," Cornell University, mimeo.

[12] Farber, H.S. and R. Gibbons (1996): "Learning and Wage Dynamics," Quarterly Journal of Economics, 111:1007-1047.

[13] Gibbons, R. and L. Katz (1991): "Layoffs and Lemons," Journal of Labor Economics, 9:351-380.

[14] Gibbons, R. and M. Waldman (1999): "A Theory of Wage and Promotion Dynamics inside Firms," Quarterly Journal of Economics, 114:1321-1358.

[15] Gibbons, R. and M. Waldman (2006): "Enriching a Theory of Wage and Promotion Dynamics Inside Firms," Journal of Labor Economics, 24: 59-107.

[16] Gibbs, M. (1995): "Incentive compensation in a coporate hierarchy," Journal of Accounting and Economics, 19: 247-277.

[17] Gibbs, M. and W. Hendricks (2004): "Do Formal Salary Systems Really Matter?" Industrial and Labor Relations Review, October. 
[18] Hamilton, T (1994): Time Series Analysis. Princeton University Press: Princeton, NJ.

[19] Hause, J. (1980): "The Fine Structure of Earnings and the On-the-Job Training Hypothesis," Econometrica, 48: 1013-29.

[20] Jacob, B. and L. Lefgren (2008): "Can Principals Identify Effective Teachers? Evidence on Subjective Performance Evaluation in Education," Journal of Labor Economics, Vol. 26(1): 101-136.

[21] Kahn, L. (2009): "Asymmetric Information between Employers," Yale University, mimeo.

[22] Kahn, L. (2010): "The Long-Term Labor Market Consequences of Graduating from College in a Bad Economy," Labour Economics, Vol. 17(2): 303-316.

[23] Lange, F. (2007): "The Speed of Employer Learning." Journal of Labor Economics, 25: 1-35.

[24] Lazear, E. and S. Rosen (1981): "Rank-order Tournaments as Optimum Labor Contracts," Journal of Political Economy, 89(5): 841-864.

[25] MaCurdy, T.(1982) "The Use of Time Series Processes to Model the Error Structure of Earnings in Longitudinal Data Analysis," Journal of Econometrics, 18: 83-114.

[26] Medhoff, J. and K. Abraham (1980): "Experience, Performance and Earnings," Quarterly Journal of Economics, 95: 703-736.

[27] Medhoff, J. and K. Abraham (1981): "Are those paid more really more productive? The case of experience," Journal of Human Resources, 16: 186-216.

[28] Murphy, K. J. (1991): "Merck \& Co., Inc. (A), (B), \& (C)," Harvard Business School Press, Boston, MA. 
[29] Oreopoulos, P., T. von Wachter and A. Heisz (2009),"The Short- and Long-Term Career Effects of Graduating in a Recession: Hysteresis and Heterogeneity in the Market for College Graduates," Columbia University, mimeo.

[30] Schönberg, U. (2007): "Testing for Asymmetric Employer Learning" Journal of Labor Economics, 25, pp. 651-692.

[31] Waldman, M. (1984): "Job Assignment, Signalling and Efficiency," RAND Journal of Economics, 15: 255-267.

\section{A More General Class of Models}

In section 2 , we have presented a model with particular productivity and learning structures. In this section, we show a more general class of models of learning about worker productivity, drawing from Hamilton (1994). We will show how to derive the second moment matrices of productivity signals and wages in this larger class of models. To estimate the parameters of these models, one naturally will fit the predicted and the observed second moment matrices of productivity signals and wages.

\section{I.1 The Productivity Process}

In period 0 (before production starts), individuals are endowed with a $\left(n_{q} x 1\right)$-vector of productivity parameters $\theta_{i, 0}$ with $E\left[\theta_{i, 0}\right]=0$ and $E\left[\theta_{i, 0} \theta_{i, 0}^{\prime}\right]=P_{0}$. In subsequent periods, productivity evolves according to a stochastic process represented by the stochastic difference equation:

$$
\begin{aligned}
\theta_{i, t+1}= & \Phi \theta_{i, t}+\varepsilon_{i, t+1}^{\theta} \\
& \varepsilon_{i, t+1}^{\theta} \sim\left(0, R_{\theta}\right)
\end{aligned}
$$


This implies that the productivity states in period 1, the first period of actual production are $\theta_{i, 1}=\Phi \theta_{i, 0}+\varepsilon_{i, 1}^{\theta}$.

\section{I.2 Prediction in the Initial Period}

Before any production takes place, firms draw a signal about $\theta_{i 0}$. This signal is summarized by an initial $\left(n_{z} x 1\right)$ vector of signals $z_{i, 0}$. This vector is not observed in the data, but represents the information available to firms at the beginning of an individual's career.

$$
\begin{aligned}
z_{i, 0}= & H_{0}^{\prime} \theta_{i, 0}+\varepsilon_{i, 0}^{z} \\
& \varepsilon_{i, 0}^{z} \sim N\left(0, R_{z, 0}\right)
\end{aligned}
$$

The dimensions of $\left(H_{0}, \varepsilon_{i, 0}^{z}, R_{z, 0}, P_{0}\right)$ are implicitly defined to conform to $z_{i, 0}$ and $\theta_{i, 0}$.

Based on the signal vector $z_{i, 0}$ firms predict the state $\theta_{i, 0}$ :

$$
\begin{aligned}
\widehat{\theta}_{i, 0 \mid 0} & =P_{0} H_{0}\left(H_{0}{ }^{\prime} P_{0} H_{0}+R_{z, 0}\right)^{-1} z_{i, 0} \\
& =K_{z} z_{i, 0}
\end{aligned}
$$

Firms set wages based on this predicted state $\widehat{\theta}_{i, 0 \mid 0}$ taking into account that productivity will evolve between the pre-period and period 1 according to equation (10). Firms best guess about productivity in period 1 is:

$$
\begin{aligned}
\widehat{\theta}_{i 1 \mid 0} & =\Phi \widehat{\theta}_{i 0 \mid 0} \\
& =\Phi K_{z} z_{i, 0}
\end{aligned}
$$

and the posterior variance of the expectation error is:

$$
P_{1 \mid 0}=\Phi\left(P_{0}-K_{z} H_{0}^{\prime} P_{0}\right) \Phi^{\prime}+R_{\theta}
$$




\section{I.3 The Recursion}

At the end of each period $t>0$, a new $\left(n_{x} x 1\right)$-signal vector $x_{i t}$ is drawn by the firm.

$$
\begin{aligned}
x_{i, t}= & H_{x}^{\prime} \theta_{i, t}+\varepsilon_{i, t}^{x} \\
& \varepsilon_{i, t}^{x} \sim N\left(0, R_{x}\right)
\end{aligned}
$$

Based on this signal, the expected posterior of $\theta_{i t}$ conditional on $x_{i t}$ is:

$$
\begin{aligned}
\widehat{\theta}_{i t \mid t} & =\widehat{\theta}_{i, t \mid t-1}+P_{t \mid t-1} H_{x}\left(H_{x}{ }^{\prime} P_{t \mid t-1} H_{x}+R_{x}\right)^{-1}\left(x_{i, t}-H_{x}^{\prime} \widehat{\theta}_{i t \mid t-1}\right) \\
& =\widehat{\theta}_{i t \mid t-1}+K_{t}\left(x_{i t}-H_{x}^{\prime} \widehat{\theta}_{i t \mid t-1}\right) \\
& =\left(1-K_{t} H_{x}^{\prime}\right) \widehat{\theta}_{i t \mid t-1}+K_{t} x_{i t}
\end{aligned}
$$

Again, when firms form expectation they account for the evolution in productivity described in equation (10). Therefore firms best guess about productivity in period $t+1$ is:

$$
\begin{aligned}
\widehat{\theta}_{i t+1 \mid t} & =\Phi \widehat{\theta}_{i t \mid t} \\
& =\Phi\left(1-K_{t} H_{x}^{\prime}\right) \widehat{\theta}_{i t \mid t-1}+\Phi K_{t} x_{i t}
\end{aligned}
$$

The variance of the expectation error then evolves according to

$$
P_{t+1 \mid t}=\Phi\left(P_{t \mid t-1}-K_{t} H_{x}^{\prime} P_{t \mid t-1}\right) \Phi^{\prime}+R_{\theta}
$$

This defines the complete prediction problem of the firm. The parameters are $\left(P_{0}, R_{z, 0}, R_{x}, R_{\theta}, H_{x}, H_{0}, \Phi\right)$ 


\section{I.4 Wages}

So far, we have described how the vector of individual productivity states $\theta_{i t}$ and the expectation of this state evolves over time. One component of the individual productivity state is $q_{i t}$, the idiosyncratic component of log productivity. We now show how log wages are related to log productivity. Because we assume that labor markets are frictionless spot markets and all information is common, we have that wages $W_{i t}^{*}$ equal expected productivity: $W_{i t}^{*}=E\left[Q(x, t) Q_{i t} \mid I^{t}\right]=E\left[Q(x, t) \exp \left(q_{i t}\right) \mid I^{t}\right]$. Here $Q(x, t)$ is a productivity profile common to all individuals and $Q_{i t}$ represents individual productivity and $I^{t}$ represents the information set available at time $t$. We assume also that wages are measured with multiplicative measurement error $\Omega_{i t}$.

We have made a number of normality assumptions. One advantage of these assumptions is that expected log productivity $\widehat{q}_{i t}$ is normally distributed in each period. We can therefore write:

$$
\begin{aligned}
W_{i t} & =Q(x, t) E\left[Q_{i, t} \mid I_{i t}\right] \Omega_{i t} \\
& =Q(x, t) E\left[\exp \left(q_{i, t}\right) \mid I_{i t}\right] \Omega_{i t}=Q(x, t) \exp \left(\widehat{q}_{i t}+\frac{1}{2} v(t)\right) \Omega_{i t}
\end{aligned}
$$

where $v(t)$ is the variance of the expectation of log productivity. Taking logs, we obtain

$$
\begin{aligned}
w_{i t} & =\left(q(x, t)+\frac{1}{2} v(t)\right)+\widehat{q}_{i t}+\omega_{i t} \\
& =h(x, t)+\widehat{q}_{i t}+\omega_{i t}
\end{aligned}
$$

where $\omega_{i t}$ is the noise in the measurement error with variance $\sigma_{\omega}^{2}$. We assume that $\omega_{i t}$ is uncorrelated with all other variables in the model.

We residualize wages to remove the common age profile $h(x, t)$ and denote the residual as $r_{i t}$. 


\section{I.5 Link to Observable Data: A State-Space Specification}

The next task is to derive the second moments that the model implies for observable quantities $\left(r_{i t}, p_{i t}\right)$. We note that our problem takes the form of a linear state-space specifications. The states that describe individuals are the individual productivity states $\theta_{i t}$ as well as the expectations firms hold $\widehat{\theta}_{i t}$. We stack these two vectors and denote the state vector by $\xi_{i t}=\left(\begin{array}{ll}\widehat{\theta}_{i t} & \theta_{i t}\end{array}\right)^{\prime}$. The states evolve in a linear stochastic way and the observed data is linearly related to the states. We denote the observed data as $y_{i t}=\left(\begin{array}{ll}r_{i t} & p_{i t}\end{array}\right)^{\prime}$.

The linear state space model consists of three parts. First, we need to specify how the state evolves. This is done in equation (18). Second, we need to specify how the states map into observed variables. This measurement equation is given by (19). Finally, we need to specify the distribution of the initial state $\xi_{i 1}$, the forcing variables $v_{i t}$, and the unobservable noise in the measurement equation $e_{i t}$.

$$
\begin{aligned}
\xi_{i t+1} & =F_{t} \xi_{i t}+v_{i t+1} \\
y_{i t} & =M \xi_{i t}+e_{i t} \\
\xi_{i 1} & =\left(\begin{array}{c}
\Phi K_{z} z_{i, 0} \\
\theta_{i 1}
\end{array}\right)
\end{aligned}
$$

The matrix M has as many rows as there are observable objects. The vector $e_{i t}$ contains the noise in the measurement equations. The matrix $F_{t}$ is given by

$$
F_{t}=\left(\begin{array}{cc}
\Phi\left(1-K_{t} H_{x}^{\prime}\right) & \Phi K_{t} H_{x}^{\prime} \\
0 & \Phi
\end{array}\right)
$$

and the innovation $v_{i t+1}$ to the state vector is defined as:

$$
v_{i t+1}=\left(\begin{array}{c}
\Phi K_{t} \varepsilon_{i t}^{x} \\
\varepsilon_{i t}^{\theta}
\end{array}\right)
$$


The $\left(K_{z}, K_{t}\right)$-matrices were implicitly defined in equations (12) and (14) above.

\section{I.6 The 2nd Moment Matrix of Observables}

We can now derive the variance-covariance matrix for the observables $y_{i t}$ and $y_{i \tau}$. Without loss of generality, we can limit ourselves to $\tau \geq t$.

Because $e_{i t}$ contains only measurement error, we can write the second moment matrices of the observables as follows:

$$
E\left[y_{i t} y_{i \tau \geq t}^{\prime}\right]=M E\left[\xi_{i t} \xi_{i \tau}^{\prime}\right] M^{\prime}+E\left[e_{i t} e_{i \tau}^{\prime}\right]
$$

The $M$ are deterministic and we therefore just have 2 components $E\left[\xi_{i t} \xi_{i \tau}^{\prime}\right]$, and $E\left[e_{i t} e_{i \tau}^{\prime}\right]$ that need to be determined as functions of the parameters of the model. The matrix $E\left[e_{i t} e_{i \tau}^{\prime}\right]$ is 0 for $\tau \neq t$ and is directly given from the is variance-covariance matrix of measurement error within $t$. We therefore simply need to determine how $E\left[\xi_{i t} \xi_{i \tau}^{\prime}\right]$ is related to the parameters.

Tedious, but straightforward algebra yields

$$
E\left[\xi_{i t} \xi_{i \tau}^{\prime}\right]=\sum_{j=2}^{j=t}\left\{\left(\prod_{l=j}^{l=t-1} F_{l}\right) E\left[v_{i, j} v_{i, j}^{\prime}\right]\left(\prod_{l=j}^{l=\tau-1} F_{l}\right)^{\prime}\right\}+\left(\prod_{l=1}^{l=t-1} F_{l}\right) E\left[\xi_{i 1} \xi_{i 1}^{\prime}\right]\left(\prod_{l=1}^{l=\tau-1} F_{l}\right)^{\prime}
$$

where

$$
E\left[\xi_{i 1} \xi_{i 1}^{\prime}\right]=\left(\begin{array}{cc}
\Phi K_{z}\left(H_{0}^{\prime} P_{0} H_{0}+R_{z}\right) K_{z}^{\prime} \Phi^{\prime} & \Phi K_{z} H_{0}^{\prime} P_{0} \Phi^{\prime} \\
\Phi P_{0} H_{0} K_{z}^{\prime} \Phi^{\prime} & \Phi P_{0} \Phi^{\prime}+R_{\theta}
\end{array}\right)
$$

and

$$
E\left[v_{i, j} v_{i, j}^{\prime}\right]=E\left(\begin{array}{cc}
\Phi K_{j-1} R_{x} K_{j-1}^{\prime} \Phi^{\prime} & 0 \\
0 & R_{\theta}
\end{array}\right)
$$


We have thus shown how to generate $E\left[y_{t} y_{\tau}\right]$ as functions of the parameters $\left(P_{0}, R_{z, 0}, R_{x}, R_{\theta}, H_{x}, H_{0}, \Phi\right)$ and the measurement matrix for any dynamic specification of productivity that follows equation (10) and any normal learning model that follows equations (11) and (13).

\section{I.7 The Nested Model as a Member of the General Linear State Space Models}

In this Appendix, we have described how the second moment of observable variables is linked to the parameters of a general linear learning model. The nested model encountered in Section 2 is a special case of such a linear learning model. We now show in the remainder of thist appendix what the nested model implies for the parameter matrices of the learning model: $\left(P_{0}, R_{z, 0}, R_{x}, R_{\theta}, H_{x}, H_{0}, \Phi\right)$ and $M$. This will allow us to implement equation (20) together with equations (21), (22), and (23) to generate the covariance matrices of the wage residuals and performance ratings.

Define first the individual productivity states as $\xi_{i t}=\left(\widehat{\theta}_{i t}, \theta_{i t}\right)^{\prime}$ where:

$$
\theta_{i t}=\left(\begin{array}{c}
q_{i t} \\
\kappa_{i} \\
\varepsilon_{i t}^{p}
\end{array}\right)
$$

Note here that we let the individual chumminess term $\varepsilon_{i t}^{p}$ enter as an individual state.

The individual state evolves as

$$
\begin{aligned}
\theta_{i t+1} & =\left(\begin{array}{c}
q_{i t+1} \\
\kappa_{i} \\
\varepsilon_{i t+1}^{p}
\end{array}\right)=\left(\begin{array}{lll}
1 & 1 & 0 \\
0 & 1 & 0 \\
0 & 0 & \rho
\end{array}\right)\left(\begin{array}{c}
q_{i t} \\
\kappa_{i} \\
\varepsilon_{i t}^{p}
\end{array}\right)+\left(\begin{array}{c}
\varepsilon_{i t+1}^{r} \\
0 \\
u_{i t+1}
\end{array}\right) \\
& =\Phi \theta_{i t}+\varepsilon_{i t}^{\theta}
\end{aligned}
$$


The vector $v_{i t+1}$ is therefore given by $v_{i t+1}=\left(\begin{array}{c}\Phi K_{t} \varepsilon_{i t}^{x} \\ \varepsilon_{i t}^{\theta}\end{array}\right)$.

Now, the measurement equation is $y_{i t}=M \xi_{i t}+e_{i t}$. Thus, we need to define $M$ and $e_{i t}$. We assume that there is measurement error in $r_{i t}$ but that $p_{i t}$ is observed without error in our data. Thus:

$$
e_{i t}=\left(\begin{array}{c}
\omega_{i t} \\
0
\end{array}\right)
$$

The measurement error variance is $\sigma_{\omega}^{2}$ and thus $E\left[e_{i t} e_{i t}^{\prime}\right]=\left(\begin{array}{cc}\sigma_{\omega}^{2} & 0 \\ 0 & 0\end{array}\right)$.

Next,

$$
M=\left(\begin{array}{llllll}
1 & 0 & 0 & 0 & 0 & 0 \\
0 & 0 & 0 & 1 & 0 & 1
\end{array}\right)
$$


Then

$$
\begin{aligned}
P_{0}= & \left(\begin{array}{ccc}
\sigma_{q}^{2} & 0 & 0 \\
0 & \sigma_{\kappa}^{2} & 0 \\
0 & 0 & 0
\end{array}\right) \\
H_{0}= & \left(\begin{array}{l}
1 \\
0 \\
0
\end{array}\right) \\
H_{x}= & \left(\begin{array}{ll}
1 & 1 \\
0 & 0 \\
0 & 1
\end{array}\right) \\
R_{z, 0}= & \sigma_{0}^{2} \\
R_{x}= & \left(\begin{array}{ll}
\sigma_{z}^{2} & 0 \\
0 & 0
\end{array}\right) \\
R_{\theta} & =\left(\begin{array}{lll}
\sigma_{r}^{2} & 0 & 0 \\
0 & 0 & 0 \\
0 & 1 & 0 \\
0 & 1 & 0 \\
0 & 0 & \rho
\end{array}\right)
\end{aligned}
$$

This specialization of the general linear state space model represents the nested model we estimate in this paper. 


\section{Identification}

We now consider the identification of the pure learning and productivity model using second moments of wages and performance signals. ${ }^{30}$ To simplify the discussion, we assume the length of individuals' careers is unbounded and that we can therefore observe these moments at arbitrarily high experience levels.

\section{II.1 The Pure Learning Model - Identification}

The pure employer-learning model allows only for learning and fixes the idiosyncratic component of worker productivity $q_{i t}=q_{i}$ over the life-cycle. This amounts to assuming that there is no heterogeneity in the drift $\kappa_{i}$ nor in the individual innovations $\varepsilon_{i t}^{r}$ and is achieved by setting $\sigma_{\kappa}^{2}=\sigma_{r}^{2}=0$. There remain 6 parameters that need to be identified: $\left(\sigma_{q}^{2}, \sigma_{0}^{2}, \sigma_{u}^{2}, \sigma_{\omega}^{2}, \rho, \sigma_{z}^{2}\right)$.

The pure learning model implies that in the limit wages asymptote towards individual productivity. Therefore, we can identify the variance of productivity $\left(\sigma_{q}^{2}\right)$ and the variance of the measurement error $\left(\sigma_{\omega}^{2}\right)$ using the variance and covariance of wages as experience grows. In particular, we obtain $\left(\sigma_{\omega}^{2}, \sigma_{q}^{2}\right)$ from $\lim _{t \rightarrow \infty}\left(v\left(w_{t}\right)\right)=\sigma_{q}^{2}+\sigma_{\omega}^{2}$ and $\lim _{t \rightarrow \infty}\left(\operatorname{cov}\left(w_{t}, w_{t+1}\right)\right)=\sigma_{q}^{2}$.

The auto-correlations of $p_{i t}$ with $p_{i t-k}$ at different lags $k$ inform us about the parameters $\left(\rho, \sigma_{u}^{2}\right)$ that govern the signal noise $\varepsilon_{i t}^{p}$. As $t$ grows, the distribution of $p_{i t}$ converges to an ergodic distribution which depends only on the parameters $\rho$ and $\sigma_{u}^{2}$. In particular, we have that $\left.\lim _{t \rightarrow \infty} v\left(p_{i t}\right)\right)=\lim _{t \rightarrow \infty} v\left(q_{i t}+\varepsilon_{i t}^{p}\right)=\sigma_{q}^{2}+\rho \frac{\sigma_{u}^{2}}{1-\rho^{2}}$ and that $\operatorname{cov}\left(p_{i t}, p_{i t+k}\right)=\operatorname{cov}\left(q_{i}+\varepsilon_{i t}^{p}, q_{i}+\rho^{k} \varepsilon_{i t}^{p}+\Sigma_{j=1}^{k} u_{i t+j}\right)=\sigma_{q}^{2}+\rho^{k} v a r\left(\varepsilon_{i t}^{p}\right)$. Combining,

\footnotetext{
${ }^{30}$ As described in the data section of this paper, the performance ratings in our data are ordinal, which implies that we do not observe variances or covariances of performance ratings with other objects. Therefore, we show how auto-correlations in performance ratings and correlations with wages at different experience levels allows us to identify models of learnings and productivity.
} 
we have that

$$
\begin{aligned}
\lim _{t \rightarrow \infty} \lim _{k \rightarrow \infty} \operatorname{cor}\left(p_{i t}, p_{i t+k}\right) & =\frac{\sigma_{q}^{2}}{\sigma_{q}^{2}+\frac{\sigma_{u}^{2}}{1-\rho^{2}}} \\
\lim _{t \rightarrow \infty} \operatorname{cor}\left(p_{i t}, p_{i t+1}\right) & =\frac{\sigma_{q}^{2}+\rho \frac{\sigma_{u}^{2}}{1-\rho^{2}}}{\sigma_{q}^{2}+\frac{\sigma_{u}^{2}}{1-\rho^{2}}}
\end{aligned}
$$

Since $\sigma_{q}^{2}$ is already identified, we get $\frac{\sigma_{u}^{2}}{1-\rho^{2}}$ from equation (24) and $\rho$ from equation $(25)$.

This leaves only two parameters $\left(\sigma_{z}^{2}, \sigma_{0}^{2}\right)$ that need to to be identified. $\sigma_{0}^{2}$ determines how much information the has about workers as they begin their careers. We can identify this parameter using the variance of wages at $t=0$, since $w_{0 i}=E\left[q_{i} \mid z_{i 0}\right]$ and $\operatorname{var}\left(w_{0 i}\right)=\operatorname{var}\left(E\left[q_{i} \mid z_{i 0}\right]\right)$. Conditional on $\sigma_{q}^{2}$, this variance declines monotonically in $\sigma_{0}^{2}$ and we can therefore identify $\sigma_{0}^{2}$ using the variance of log wages for individuals beginning their careers.

The remaining parameter $\sigma_{z}^{2}$ governs (together with the already identified $\sigma_{u}^{2}$ and $\rho$ ) how much additional information becomes available in any period. Conditional on $\left(\sigma_{0}^{2}, \sigma_{u}^{2}, \rho\right)$, the variance of $w_{1 i}=E\left[q_{i} \mid z_{0 i}, p_{1 i}, z_{1 i}\right]$ declines monotonically in $\sigma_{z}^{2}$ (as the signal becomes less informative). Therefore we can identify $\sigma_{z}^{2}$ using $\operatorname{var}\left(w_{1 i}\right)$, having already identified the other parameters of the learning model.

\section{II.2 The Pure Productivity Model - Identification}

The pure productivity model assumes that firms have full information about worker productivity and that wages equal productivity at all times. This assumption can be imposed by restricting the signal noise for the unobserved signals to $0: \sigma_{0}^{2}=\sigma_{z}^{2}=0$. There remain 6 parameters that need to be identified: $\left(\sigma_{q}^{2}, \sigma_{r}^{2}, \sigma_{u}^{2}, \sigma_{\omega}^{2}, \sigma_{\kappa}^{2}, \rho\right)$.

Because wages at all times equal expected productivity, we can write $\Delta w_{i t}=$ $w_{i t+1}-w_{i t}=\kappa_{i}+\varepsilon_{i t+1}^{r}+\omega_{i t+1}-\omega_{i t}$. This implies that $\operatorname{cov}\left(\Delta w_{i t}, \Delta w_{i t+2}\right)=\sigma_{\kappa}^{2}$, 
$\operatorname{cov}\left(\Delta w_{i t}, \Delta w_{i t+2}\right)=\sigma_{\kappa}^{2}-\sigma_{\omega}^{2}$, and $\operatorname{var}\left(\Delta w_{i t}\right)=\sigma_{\kappa}^{2}+\sigma_{r}^{2}+2 * \sigma_{\omega}^{2}$. This system is triangular and can easily be solved for the parameters $\left(\sigma_{\kappa}^{2}, \sigma_{r}^{2}, \sigma_{\omega}^{2}\right)$. Furthermore, we can identify $\sigma_{q}^{2}$ using $\operatorname{var}\left(w_{i 0}\right)=\sigma_{q}^{2}+\sigma_{\omega}^{2}$.

The remaining parameters that need to be identified are the parameters $\left(\rho, \sigma_{u}^{2}\right)$ that govern the noise in the performance rating $p_{i t}$. To identify these we rely on the correlations between wages and performance ratings:

$$
\operatorname{corr}\left(p_{i t}, w_{i t}\right)=\frac{\operatorname{var}\left(q_{i t}\right)}{\left(\operatorname{var}\left(q_{i t}\right)+\operatorname{var}\left(\varepsilon_{i t}^{p}\right)\right)^{1 / 2}\left(\operatorname{var}\left(q_{i t}\right)+\sigma_{\omega}^{2}\right)^{1 / 2}}
$$

Since all the productivity parameters are identified, we can treat var $\left(q_{i t}\right)$ and $\sigma_{\omega}^{2}$ as known. Thus, eq (26) solves for the variance of the signal noise $\operatorname{var}\left(\varepsilon_{i t}^{p}\right)$ for arbitrary $t$ :

$$
\lim _{t \rightarrow \infty} \operatorname{var}\left(\varepsilon_{i t}^{p}\right)=\frac{\sigma_{u}^{2}}{1-\rho^{2}} \Rightarrow \sigma_{u}^{2}=\left(1-\rho^{2}\right) \lim _{t \rightarrow \infty} \operatorname{var}\left(\varepsilon_{i t}^{p}\right)
$$

Since we know the $\operatorname{var}\left(\varepsilon_{i t}^{p}\right)$ for arbitrary $t$, we can exploit equation (4) to get

$$
\rho^{2}=\frac{\operatorname{var}\left(\varepsilon_{i t+1}^{p}\right)-\lim _{t \rightarrow \infty} \operatorname{var}\left(\varepsilon_{i t}^{p}\right)}{\operatorname{var}\left(\varepsilon_{i t}^{p}\right)-\lim _{t \rightarrow \infty} \operatorname{var}\left(\varepsilon_{i t}^{p}\right)}
$$

These last two equations therefore deliver the parameters $\rho$ and $\sigma_{u}^{2}$. We have thus established the identification of both the pure learning and the pure productivity model. We will now turn to the estimation of these models.

\section{Attrition}

To obtain the results reported in the main body of the paper we assumed that the individuals in our data are representative of the population of workers from which the firm draws its white-collar workforce. That is, we assume that wages or productivity 
of individuals with the same experience level do not depend on tenure at the firm. We can investigate this assumption in reduced form using wages and performance measures. Figure A-1 and Figure A-2 show by how much log salary and the performance of first-year workers of various ages differ from the incumbent workforce of the same age. We observe that wages of new entrants and the incumbent work-force are quite similar, but that performance is somewhat lower among new entrants compared with the existing work-force. Table A-1 illustrates the mechanism that gives rise to this relation. This table reports how the probability of exiting the firm depends on the log salary as well as on the performance ratings of individuals, after controlling for age. $^{31}$

Table A-1: Probability of Exit from the Firm

The table illustrates that the performance ratings, but not the salary are statistically significant predictors of attrition from the sample. In particular, individuals with very low ratings are significantly more likely to attrit from the sample. The linear probability model indicates that being in the lowest decile of the performance distribution raises the attrition probability by about 5 percentage points compared to being in the second decile. Further moves up in the performance distribution have a much smaller effect on attrition from the sample. These point estimates therefore support the notion that leaving the firm is endogenous to performance rankings and that the effect of performance on attrition is particular strong for very low ratings. However, the $R^{2}$ of the linear probability model also suggests that the overall impact of turn-over based on performance ratings is small.

To be sure that our estimates reported in the paper are not spurious due to non-

\footnotetext{
${ }^{31}$ We control for performance ratings using dummies for each decile within the distribution of performance rankings. These deciles are populated even though the performance ratings themselves are only reported on a 5 point scale, because individuals ratings are regression adjusted for race, gender, and education in a flexible manner.
} 
random attrition, we estimate an attrition corrected version of our model. For this purpose, we assume that individuals entering the firm are randomly drawn from the population, but that the separation from the firm is governed by the relationship captured by the Probit regression reported in column 1 of the Table A-1. That is, we assume that the probability of separating is given by

$$
\Phi\left(\beta_{w} w a g e+\beta_{P D}^{\prime} P D_{i}+\beta_{a} a g e\right)
$$

where $\Phi($.$) is the standard normal distribution, P D_{i}$ denotes a vector of performance deciles and the parameters $\left(\beta_{w}, \beta_{P D}^{\prime}, \beta_{a}\right)$ are obtained from column 1 of Table A-1.

We estimate the parameters of the learning and productivity model using a simulated method of moments. That is, we simulate a sample consisting of 1,000 workers entering the firm at each experience level for a total of 40,000 workers entering with experience levels 1-40. For a given point in the parameter space of the nested model of learning and productivity (described in section 2), we simulate a history of wages and performance ratings under the assumption that no worker attrits. We then apply the selection rule (29) to this sample and thus obtain a selected sample. Using this selected, simulated sample, we generate the same moments (variance of wages, performance and pay autocorrelation, pay-performance correlations at various leads and lags) that we use in Section 2 to estimate the parameters of the model. We can then estimate the parameters by minimizing the distance between the observed and simulated moments in the same manner as before. ${ }^{32}$

In Table A-2 we report the attrition corrected parameters.

\section{Table A-2: Parameter Estimates from Attrition Corrected Model}

\footnotetext{
${ }^{32}$ Note that we estimate the parameters of the selection rule first. This is possible, because we assume that conditional on performance, wages, and age, attrition is random. We can thus treat the observed wages and performance measures as exogenous in estimating the parameters of the attrition model. Because we estimate the parameters of the attrition rule separately, we do not expect the fit of the model to improve as we correct for attrition.
} 
To facilitate comparison this table also shows the parameter estimates reported for the full model in table $2 .{ }^{33}$ The estimated parameters are close. In fact, the fit of the attrition corrected and the uncorrected estimates is almost identical and none of our conclusions on the relative importance of learning or productivity evolution are sensitive to using the attrition corrected or the uncorrected estimates. Overall, we therefore believe that our results are robust to attrition based on observed performance or wages.

\footnotetext{
${ }^{33}$ The computational burden of implementing the attrition correction is significant. We therefore imposed two restrictions on the parameters to reduce the run-time. Because the main model provides little evidence for measurement error in wages, we restricted the variation of measurement error to 0 . We also restricted the auto-regressive parameter in the performance ranking to 0.64. Even after imposeing these restrictions, estimating the attrition corrected parameters on our system requires about 1 week of computing time. We therefore refrained from bootstrapping the attrition corrected standard errors.
} 
Table 1: BGH Summary Statistics

Years

1969-1988

Managers of a medium-

Data Description sized US firm in the service sector

\# Employees ${ }^{1}$

\# Employee-years

59485

\% Male

$76.2 \%$

$\%$ White

$89.4 \%$

39.02

Age

Education

$\%$ HS

$16.9 \%$

$\%$ Some College

$18.8 \%$

$\%$ College

$36.6 \%$

\% Advanced

$27.7 \%$

$\$ 53,881$

Salary ${ }^{2}$

(25447)

[ $n=54364$ ]

3.12

(0.72)

Performance $^{3}$

$[n=38933]$

Performance Distribution

$\begin{array}{ll}1 & 0.009 \\ 2 & 0.177 \\ 3 & 0.499 \\ 4 & 0.315\end{array}$

Notes: Parentheses contain standard deviations.

1. Sample includes all employees who have a pay or performance measure between the ages of 25 and 54 and at least one more pay or performance measure, with a nonmissing education variable.

2. Salary is annual base pay, adjusted to 1988 dollars.

3. Performance is a categorical variable which we recode to be between 1 and 4 , with 4 being the highest performance. 
Table 2: Parameter Estimates for 3 Models

\begin{tabular}{|c|c|c|c|}
\hline & Employer Learning & Productivity & Combined \\
\hline$\sigma_{\mathrm{q}}^{2}$ & $\begin{array}{c}0.118 \\
(0.0057)\end{array}$ & $\begin{array}{c}0.025 \\
(0.0051)\end{array}$ & $\begin{array}{c}0.037 \\
(0.0072)\end{array}$ \\
\hline$\sigma_{r}^{2}$ & - & $\begin{array}{c}0.0040 \\
(0.00032)\end{array}$ & $\begin{array}{c}0.00049 \\
(0.00040)\end{array}$ \\
\hline$\sigma_{0}^{2}$ & $\begin{array}{c}0.383 \\
(0.061)\end{array}$ & - & $\begin{array}{c}0.114 \\
(0.071)\end{array}$ \\
\hline$\sigma_{u}^{2}$ & $\begin{array}{c}0.650 \\
(0.062)\end{array}$ & $\begin{array}{c}0.405 \\
(0.031)\end{array}$ & $\begin{array}{c}0.488 \\
(0.051)\end{array}$ \\
\hline$\sigma_{\omega}{ }^{2}$ & $\begin{array}{c}0.0049 \\
(0.00021)\end{array}$ & $\begin{array}{c}0.00030 \\
(0.00048)\end{array}$ & $\begin{array}{c}2.83 e-12 \\
(4.95 e-12)\end{array}$ \\
\hline$\sigma_{\mathrm{k}}$ & - & $\begin{array}{l}0.00000027 \\
(0.0000023)\end{array}$ & $\begin{array}{c}0.00015 \\
(0.000016)\end{array}$ \\
\hline$\rho$ & $\begin{array}{c}0.645 \\
(0.0084)\end{array}$ & $\begin{array}{c}0.634 \\
(0.0084)\end{array}$ & $\begin{array}{c}0.640 \\
(0.009)\end{array}$ \\
\hline$\sigma_{z}^{2}$ & $\begin{array}{c}0.506 \\
(0.131)\end{array}$ & - & $\begin{array}{c}0.206 \\
(0.075)\end{array}$ \\
\hline
\end{tabular}


Appendix Table A-1: Probability of Exit from the Firm

\begin{tabular}{|c|c|c|}
\hline & (1) & (2) \\
\hline & Probit & $\begin{array}{c}\text { Linear Probability } \\
\text { Model }\end{array}$ \\
\hline Log wage & $\begin{array}{l}0.0154 \\
(0.034)\end{array}$ & $\begin{array}{l}0.0034 \\
(0.007)\end{array}$ \\
\hline $\begin{array}{l}\text { Performance - 2nd } \\
\text { Decile }\end{array}$ & $\begin{array}{l}-0.204^{* \star *} \\
(0.035)\end{array}$ & $\begin{array}{c}-0.0498^{\star * *} \\
(0.008)\end{array}$ \\
\hline $\begin{array}{l}\text { Performance - 3rd } \\
\text { Decile }\end{array}$ & $\begin{array}{l}-0.231^{\star \star \star} \\
(0.036)\end{array}$ & $\begin{array}{c}-0.0552^{\star \star \star} \\
(0.008)\end{array}$ \\
\hline $\begin{array}{l}\text { Performance - 4th } \\
\text { Decile }\end{array}$ & $\begin{array}{c}-0.212^{\star \star \star} \\
(0.036)\end{array}$ & $\begin{array}{c}-0.0507^{\star \star \star} \\
(0.008)\end{array}$ \\
\hline $\begin{array}{l}\text { Performance - 5th } \\
\text { Decile }\end{array}$ & $\begin{array}{c}-0.280 \star \star \star \\
(0.036)\end{array}$ & $\begin{array}{c}-0.0650 \star \star \star \\
(0.008)\end{array}$ \\
\hline $\begin{array}{l}\text { Performance - 6th } \\
\text { Decile }\end{array}$ & $\begin{array}{c}-0.350^{\star * *} \\
(0.037)\end{array}$ & $\begin{array}{c}-0.0788^{\star \star \star} \\
(0.008)\end{array}$ \\
\hline $\begin{array}{l}\text { Performance - 7th } \\
\text { Decile }\end{array}$ & $\begin{array}{l}-0.411^{\star \star *} \\
(0.037)\end{array}$ & $\begin{array}{l}-0.0895^{\star \star \star} \\
(0.008)\end{array}$ \\
\hline $\begin{array}{l}\text { Performance - 8th } \\
\text { Decile }\end{array}$ & $\begin{array}{c}-0.335^{\star \star *} \\
(0.038)\end{array}$ & $\begin{array}{c}-0.0756^{* * *} \\
(0.008)\end{array}$ \\
\hline $\begin{array}{l}\text { Performance - 9th } \\
\text { Decile }\end{array}$ & $\begin{array}{c}-0.453^{\star \star \star} \\
(0.038)\end{array}$ & $\begin{array}{l}-0.0964^{\star \star \star} \\
(0.008)\end{array}$ \\
\hline Age & $\begin{array}{c}-0.00611^{\star \star \star} \\
(0.0009)\end{array}$ & $\begin{array}{l}-0.0013 \\
(0.0002)\end{array}$ \\
\hline Constant & $\begin{array}{c}-0.657^{\star \star \star} \\
(0.043) \\
\end{array}$ & $\begin{array}{l}0.236^{\star \star \star} \\
(0.009)\end{array}$ \\
\hline $\begin{array}{l}\text { Observations } \\
\text { R-squared }\end{array}$ & 33,151 & $\begin{array}{c}33,151 \\
0.008 \\
\end{array}$ \\
\hline
\end{tabular}


Table A-2 Parameter Estimates from Attrition Corrected and Baseline Model

\begin{tabular}{ccc}
\hline & Attrition Corrected & Baseline \\
$\sigma_{\mathrm{q}}{ }^{2}$ & 0.0420 & 0.037 \\
& & $(0.0072)$ \\
$\sigma_{\mathrm{r}}{ }^{2}$ & $3.7 \mathrm{E}-04$ & 0.00049 \\
& & $(0.00040)$ \\
$\sigma_{0}{ }^{2}$ & 0.0716 & 0.114 \\
& & $(0.071)$ \\
$\sigma_{\mathrm{u}}{ }^{2}$ & 0.5025 & 0.488 \\
& & $(0.051)$ \\
$\sigma_{\omega}{ }^{2}$ & 0 & $2.83 \mathrm{e}-12$ \\
& $($ fixed) & $(4.95 \mathrm{e}-12)$ \\
$\sigma_{\mathrm{k}}$ & 0.0125 & 0.00015 \\
& 0.64 & $(0.000016)$ \\
$\rho$ & $($ fixed) & 0.640 \\
& & $(0.009)$ \\
$\sigma_{\mathrm{z}}{ }^{2}$ & 0.2464 & 0.206 \\
\hline
\end{tabular}

Reported are the attrition corrected estimates of the nested model and as comparision the uncorrected estimates ("Baseline").

Standard errors for the attrition corrected estimates are not available due to the computational burden of estimating these parameters. Standard errors for the Baseline estimates are obtained from bootstrapping 500 times. 
Figure 1: Log Wages and Performance, by Age Controlling for education, race, gender, and year effects

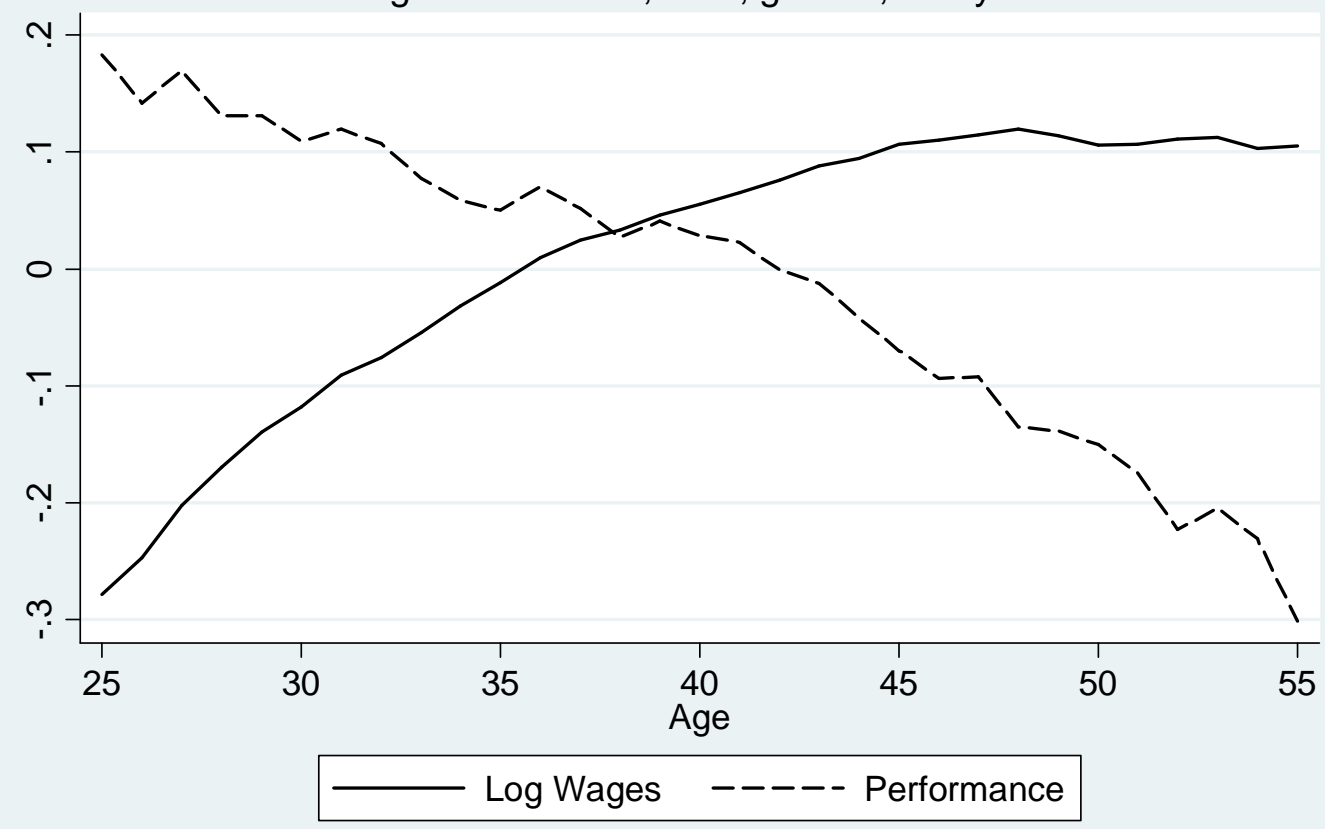

Figure 2a: Moments with 95\% Cl

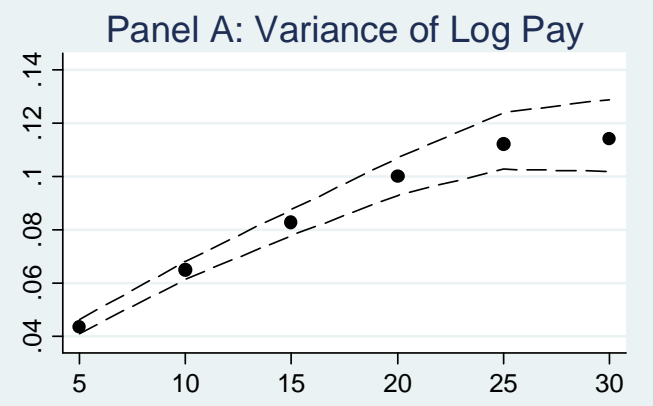

Panel B: Performance Auto-Correlations

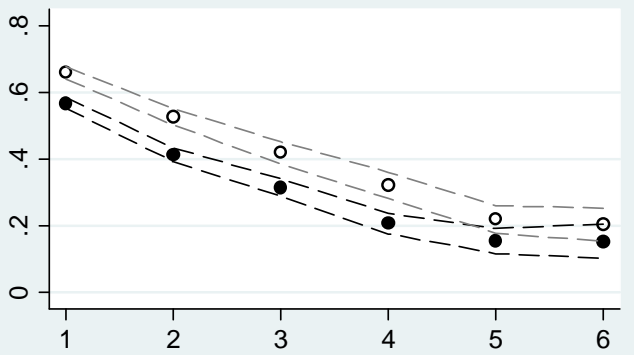

Panel C: Pay Auto-Correlations
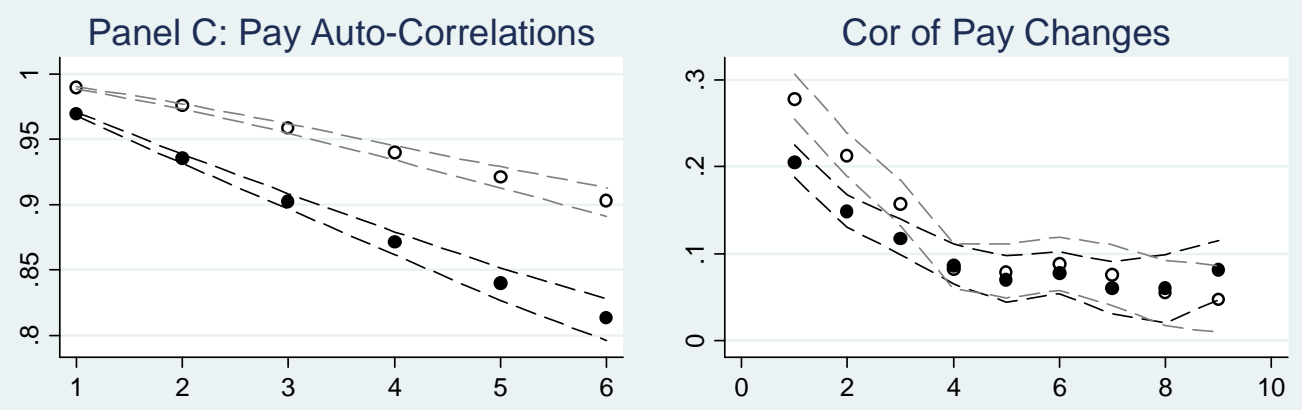


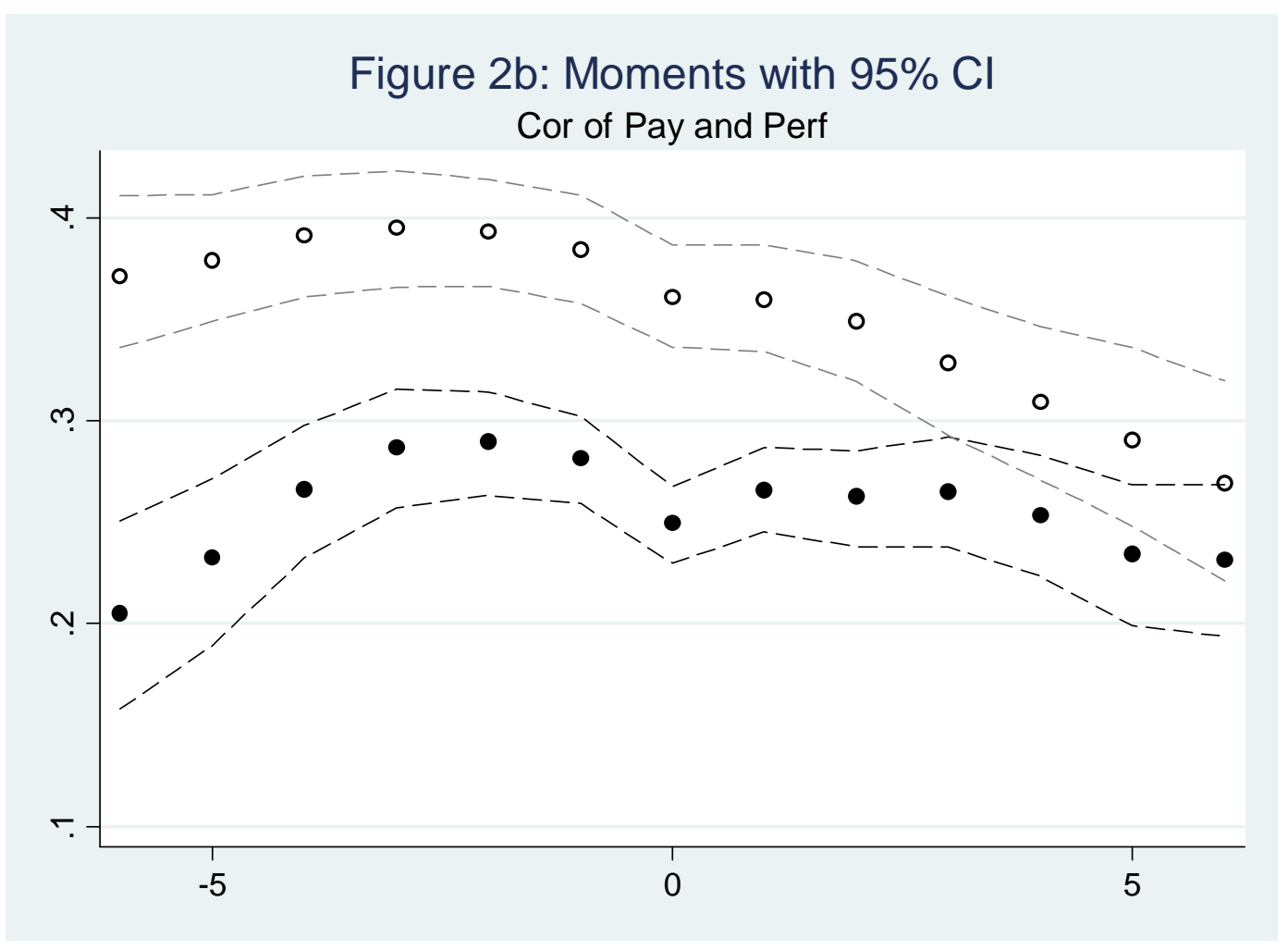

Figure 3: Results - Correlations between Pay and Performance

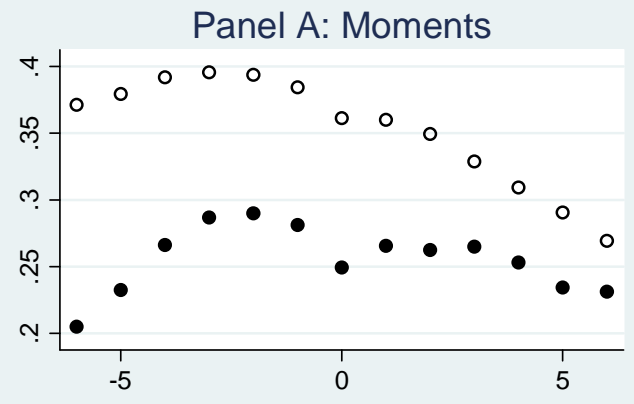

Panel B: Pure Learning Model
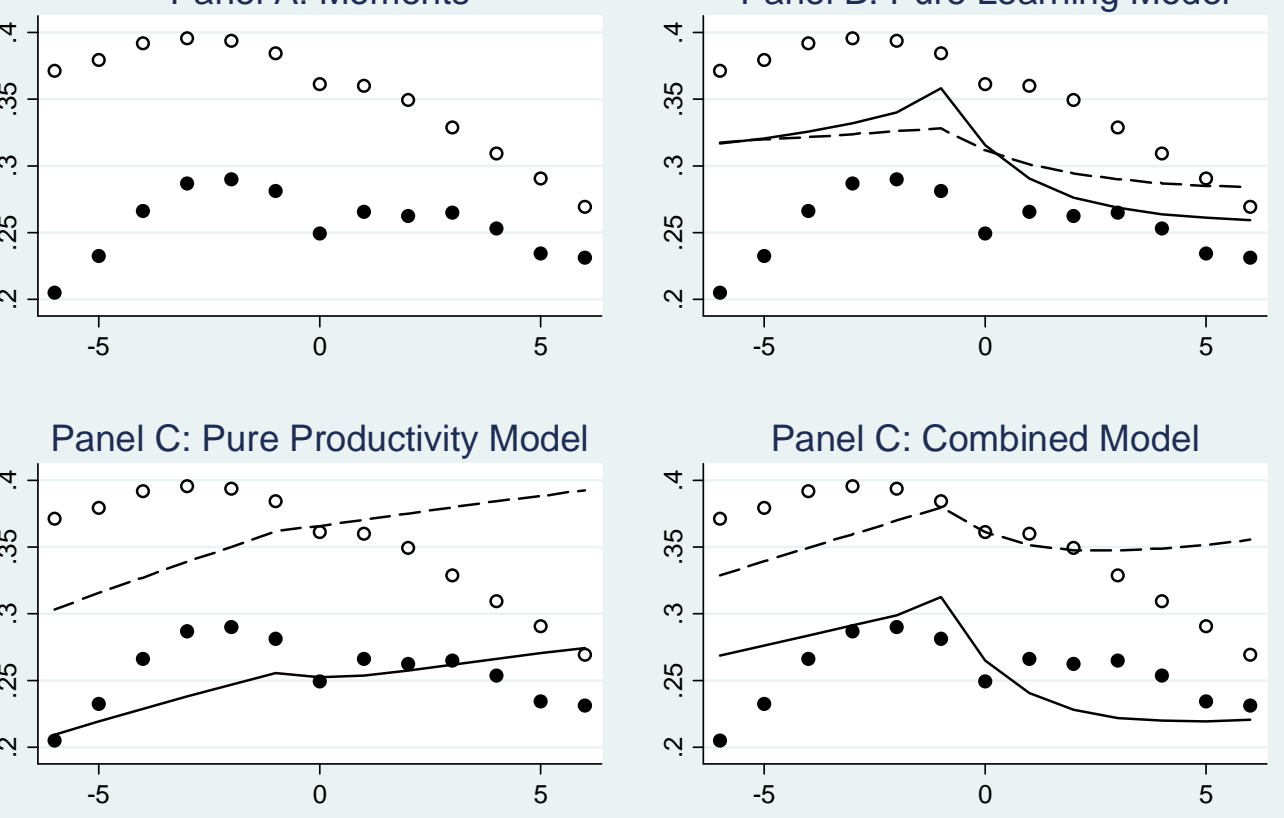
Figure 4: Results - Pure Learning Model

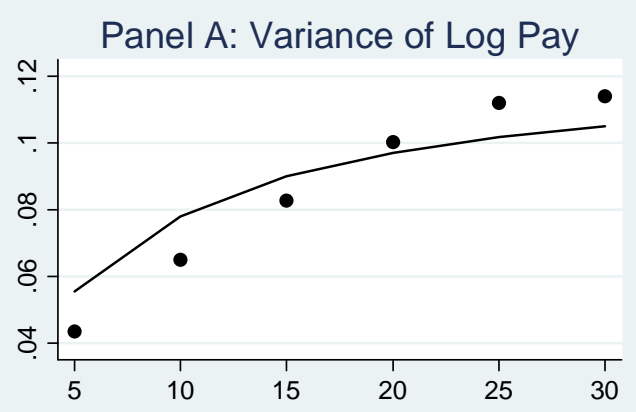

Panel B: Performance Auto-Correlations

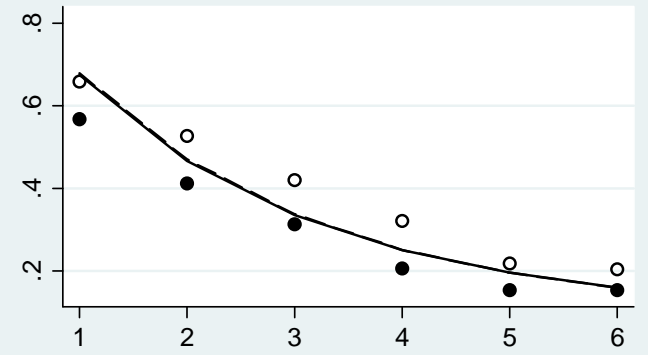

Panel C: Pay Auto-Correlations

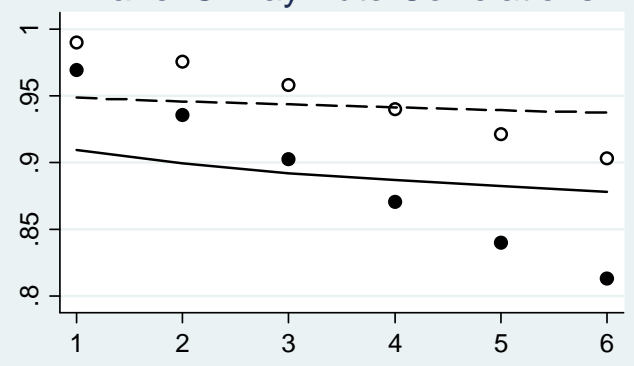

Panel D: Cor of Pay Changes

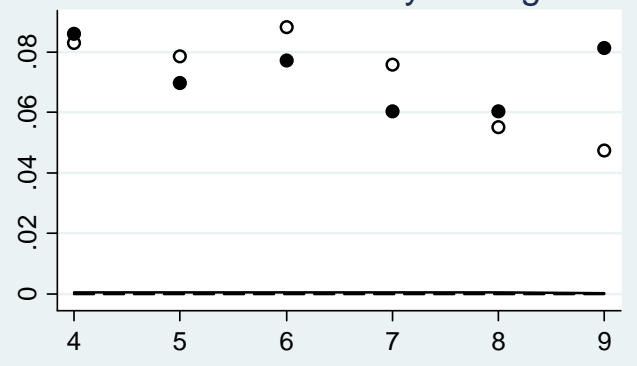

Figure 5: Results - Pure Productivity Model

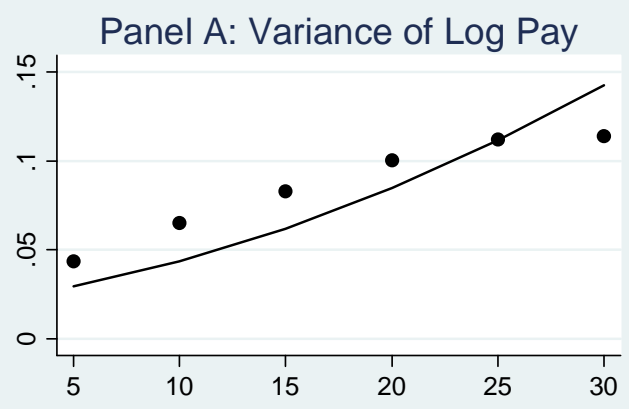

Panel B: Performance Auto-Correlations

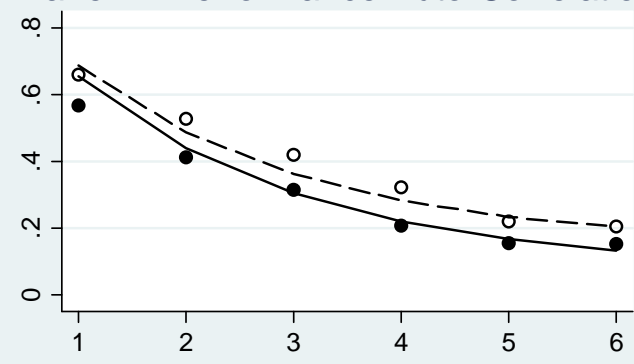

Panel C: Pay Auto-Correlations

Panel D: Cor of Pay Changes
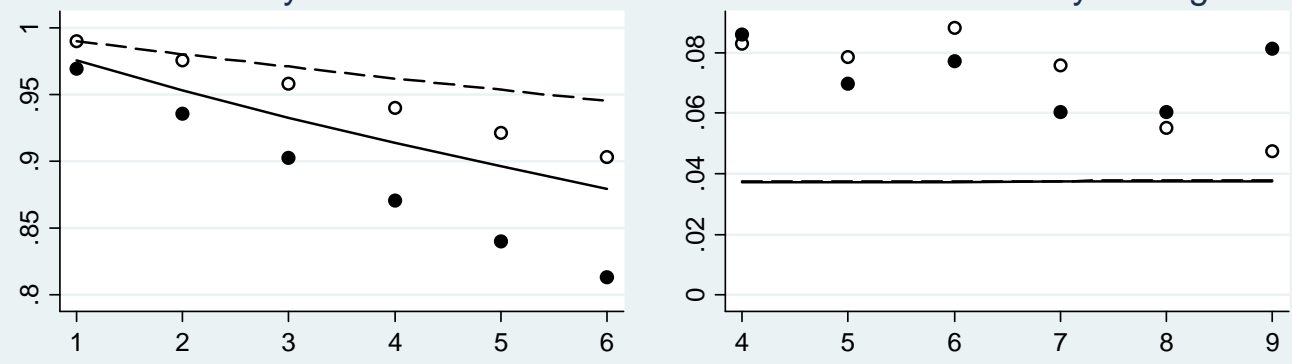
Figure 6: Results - Combined Model

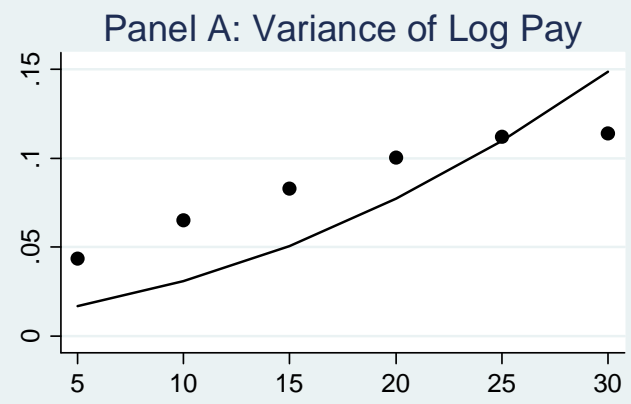

Panel B: Performance Auto-Correlations

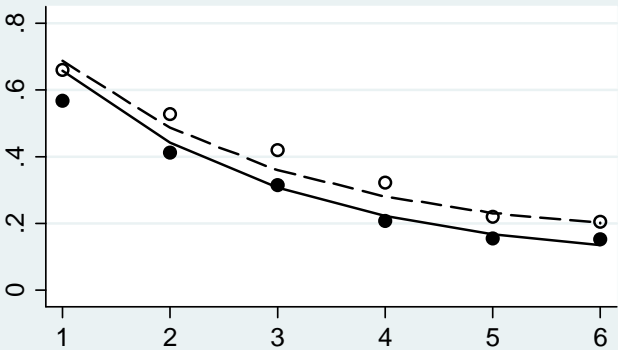

Panel C: Pay Auto-Correlations

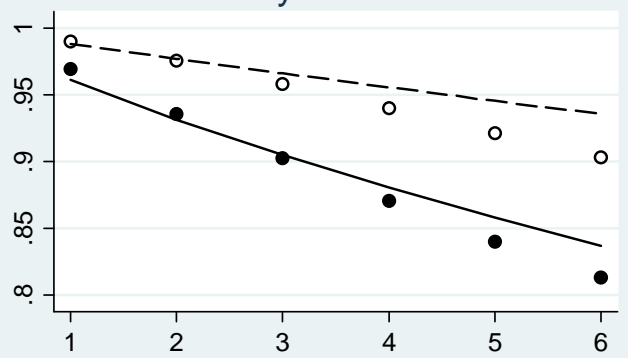

Panel D: Cor of Pay Changes

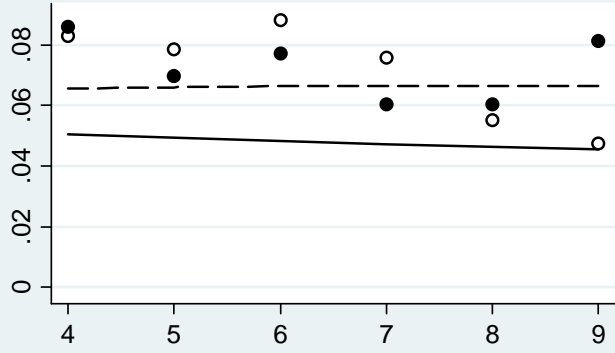

Figure 7: Productivity, Wage, and Error Variances

Full Model

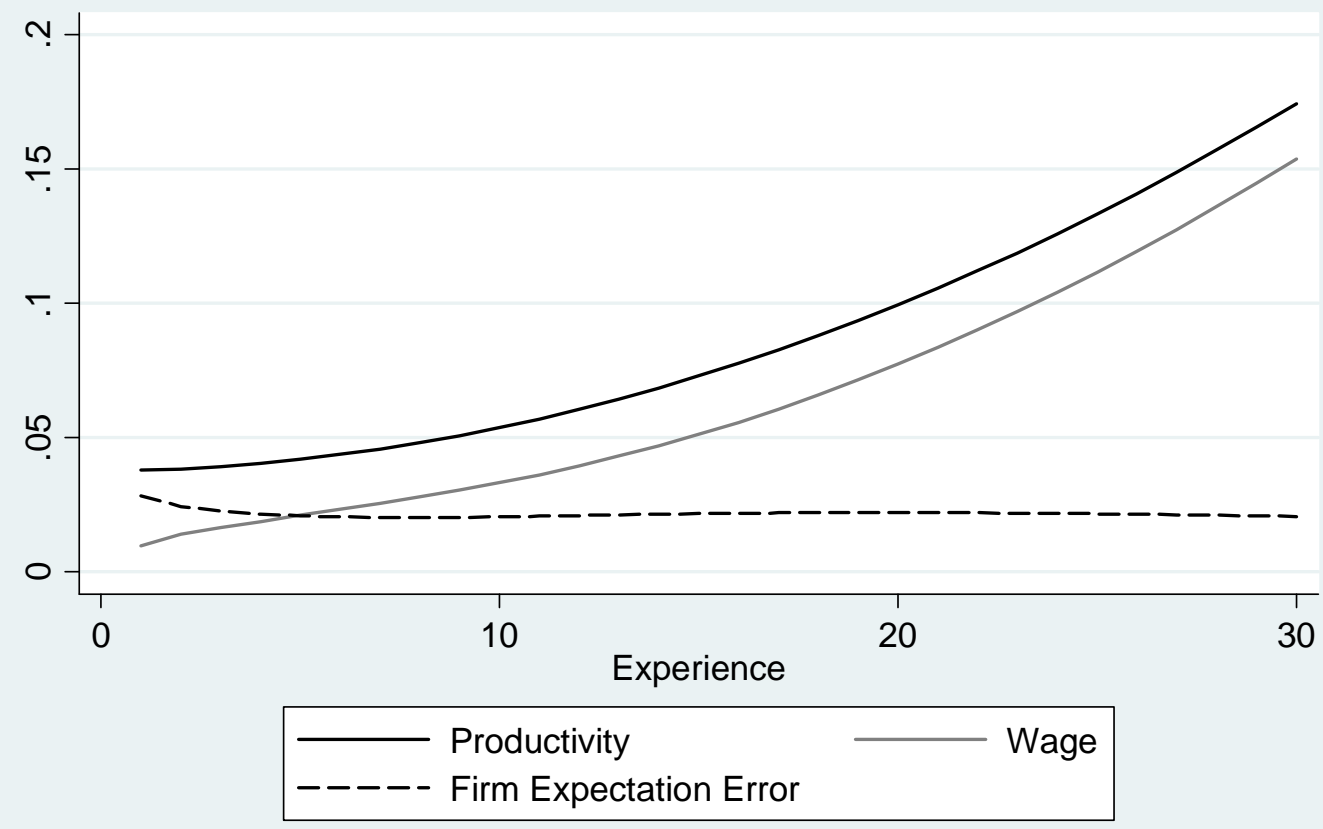


Figure A-1: Log Salary in First Year as a Function of Entry Age Controlling for age, education, race, gender, and year effects

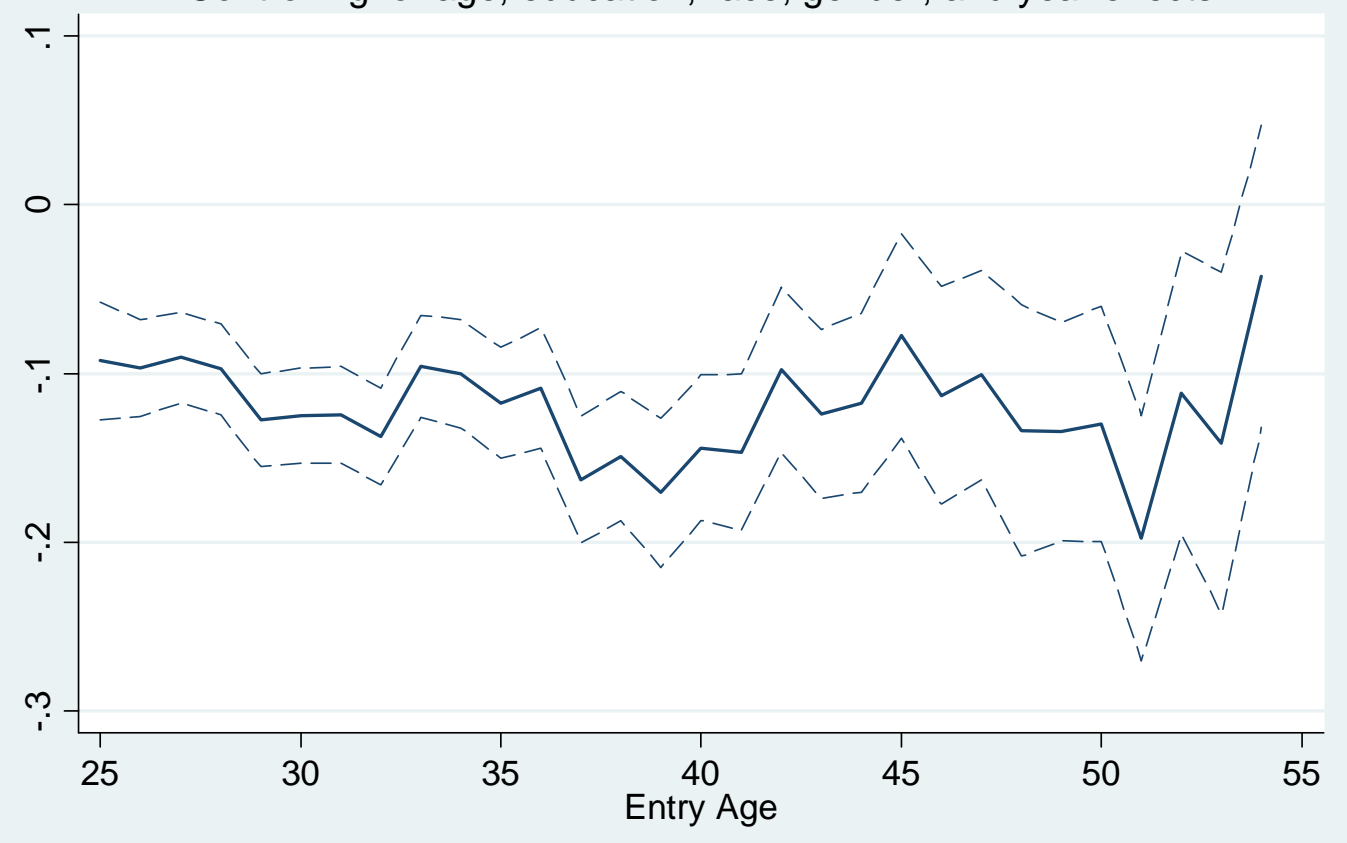

Figure A-2: Performance in First Year as a Function of Entry Age Controlling for age, education, race, gender, and year effects

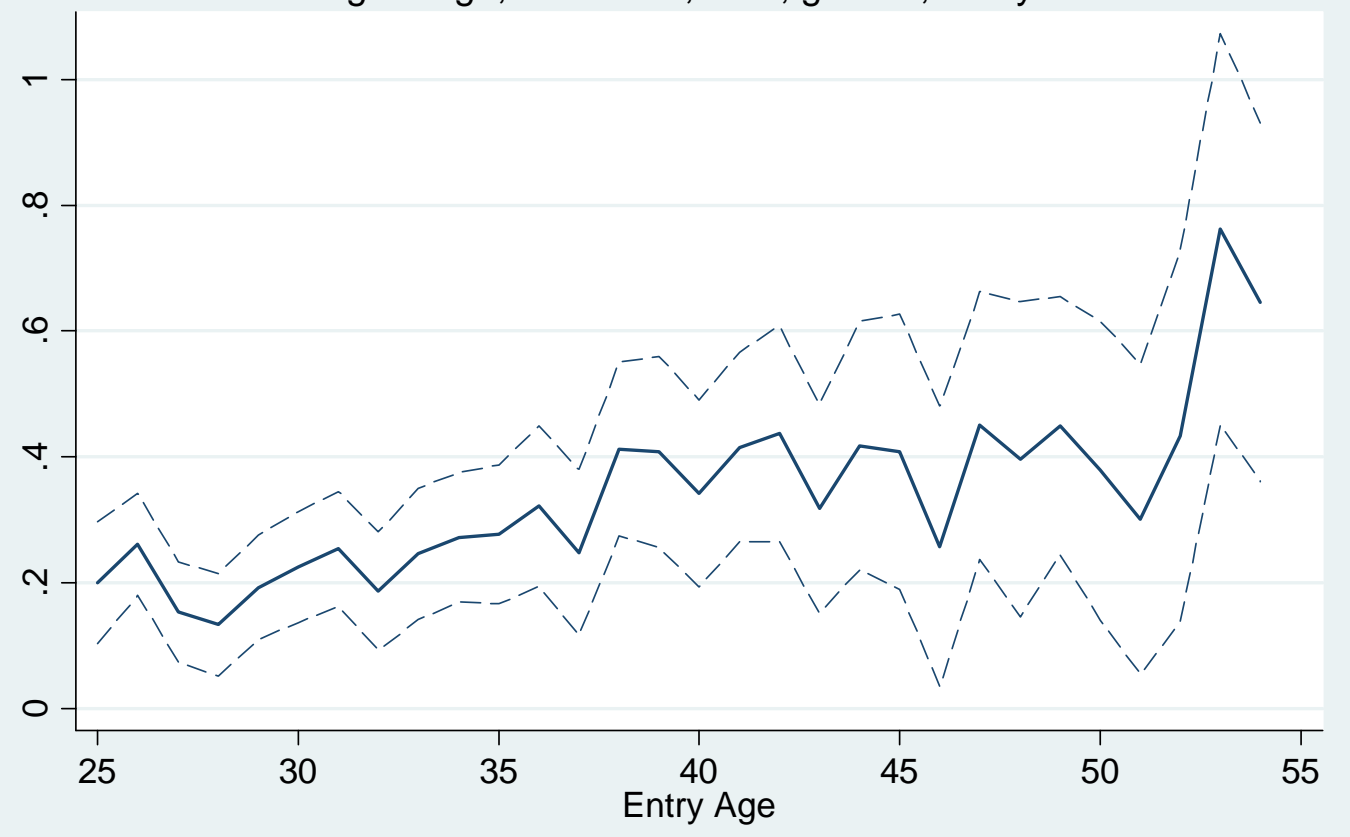

